\title{
TEORES DE POTÁSSIO, URÂNIO, TÓRIO E TAXA DE PRODUÇÃO DE CALOR RADIOGÊNICO NO EMBASAMENTO ADJACENTE ÀS BACIAS SEDIMENTARES DE CAMAMU E ALIMADA, BAHIA, BRASIL
}

\author{
Najara Santos Sapucaia', Roberto Max de Argollo² e Johildo Salomão Figueiredo Barbosa ${ }^{3}$ \\ Recebido em 26 outubro, 2005 / Aceito em 27 dezembro, 2005 \\ Received on October 26, 2005 / Accepted on December 27, 2005
}

\begin{abstract}
The bedrock adjacent to Camamu and Almada sedimentary basins is characterized mainly by rocks of granulite and amphibolite facies, with archean and paleoproterozoic ages, which belong to orogen Itabuna-Salvador-Curaçá. The units in major proportion in this context are the metatonalites associated with basic and metamonzonites belonging to Itabuna belt. In smaller area occur the Teolândia granite and the Moenda granodiorite associated with the Ipiaú band amphibolites, the charnockites and charnoenderbites of Jequié bloc, the neoproterozoic sienites and the mafic dikes. The $\mathrm{K}, \mathrm{U}$ and Th contents of the rocks vary from 0,02 to 6,33\% for $\mathrm{K}$, from < 0, 2 to 9,10 ppm for $U$ and from < 0, 4 to 64,38 ppm for Th. These contents are higher in the charnockites, Moenda granodiorite, Teolândia granite and sienites, intermediate in the metatonalites and metamonzonites and lower in the basic granulites. The heat production rates are higher in the lithologies where $\mathrm{K}, \mathrm{U}$ and $\mathrm{Th}$ are also higher, varying from 0,58 to $5,57 \mu \mathrm{W} \mathrm{m}^{-3}$. The coverage areas of such lithologies are, however, small compared with that of the metatonalitic granulites, metamonzonitic granulites and sienites where the rates vary from 0,10 to $1,44 \mu \mathrm{W} \mathrm{m}^{-3}, 0,23$ to $5,55 \mu \mathrm{W} \mathrm{m}^{-3}$ and 0,60 to $2,24 \mu \mathrm{W} \mathrm{m}^{-3}$, respectively. In this case, the heat production rates vary from 0,10 to $1,44 \mu \mathrm{W} \mathrm{m}^{-3}$. The basic granulites have the smaller rates, from 0,06 to $0,36 \mu \mathrm{W} \mathrm{m}^{-3}$. The observation of the lithologies in the margins of the two basins suggest that, in the bedrock under the younger sediments, may predominate the metatonalites, followed by the metamonzonites, with some significant participation of sienites in the Almada basin. In those lithologies, the volumetric heat production rates, with one standard deviation range, are $0,41 \pm 0,30 \mu \mathrm{W} \mathrm{m}{ }^{-3}$ for metatonalites, $0,71 \pm 0,57 \mu \mathrm{W} \mathrm{m}^{-3}$ for metamonzonites and 1,20 $\pm 0,51 \mu \mathrm{W} \mathrm{m}^{-3}$ for sienites.
\end{abstract}

Keywords: gamma-ray spectrometry, heat production in rocks, K, U and Th in rocks.

RESUMO. 0 embasamento adjacente às bacias sedimentares de Camamu e Almada é caracterizado, principalmente, por rochas das facies granulito e anfibolito, com idades arqueanas e paleoproterozoicas, pertencentes ao orógeno Itabuna-Salvador-Curaçá. As unidades em maior proporção neste contexto são os granulitos metatonalíticos associados aos granulitos básicos e metamonzoníticos pertencentes ao cinturão Itabuna. Em menor área, tem-se o granito de Teolândia e o granodiorito de Moenda associado aos anfibolitos da banda de Ipiaú, os charnockitos e charnoenderbitos do bloco Jequié, os sienitos neoproterozóicos e os diques máficos. Os teores de $\mathrm{K}$, U e Th nessas rochas variam de 0,02 a 6,33\% para o K, < 0, 2 a 9,10 ppm para o U e $<0,4$ a 64,38 ppm para 0 Th. Esses teores são mais altos nos charnockitos, no granodiorito de Moenda, no granito de Teolândia e nos sienitos, têm valores intermediários nos metatonalitos e metamonzonitos e são mais baixos nos granulitos básicos. As taxas de produção de calor nessas rochas são mais altas onde os teores de $\mathrm{K}, \mathrm{U}$ e Th são maiores, variando de 0,58 a 5, $57 \mu \mathrm{W} \mathrm{m}{ }^{-3}$. As áreas de abrangência dessas litologias são, contudo, pequena quando comparada com aquelas dos metatonalitos, metamonzonitos e sienitos onde as taxas variam de 0,10 a $1,44 \mu \mathrm{W} \mathrm{m}{ }^{-3}, 0,23$ a $5,55 \mu \mathrm{W} \mathrm{m}^{-3}$ e 0,60 a $2,24 \mu \mathrm{W} \mathrm{m}^{-3}$, respectivamente. Os granulitos básicos possuem as menores taxas, entre 0,06 a $0,36 \mu \mathrm{W} \mathrm{m} \mathrm{m}^{-3}$. A distribuição das litologias nas bordas das duas bacias sugere que, no embasamento sob seus sedimentos mais recentes, deve predominar os metatonalitos, seguidos pelos metamonzonitos e com uma participação significante de sienitos no caso da bacia de Almada. Para estas litologias, as taxas volumétricas de produção de calor, com o intervalo de um desvio padrão, são $0,41 \pm 0,30 \mu \mathrm{W} \mathrm{m}{ }^{-3}$ para os metatonalitos, $0,71 \pm 0,57 \mu \mathrm{W} \mathrm{m}^{-3}$ para os metamonzonitos e $1,20 \pm 0,51 \mu \mathrm{W} \mathrm{m}{ }^{-3}$ para os sienitos.

Palavras-chave: espectrometria gama, calor radiogênico em rochas, K, U e Th em rochas.

${ }^{1}$ Instituto de Geociências, Universidade Federal da Bahia, Rua Barão de Jeremoabo, s/n, sala 315-C, Campus da Federação, 40170-115 Salvador, Bahia, Brasil. Tel: (71) 3203-8531; Fax: (71) 3203-8501 - End. elet.: nss@cpgg.ufba.br

2Laboratório de Física Nuclear Aplicada, Instituto de Física, Universidade Federal da Bahia, Travessa Barão de Jeremoabo, s/n, Campus da Federação, 40170-280 Salvador, Bahia, Brasil. Tel: (71) 3263-6680; Fax: (71) 3235-0002 - End. elet.: robmax@ufba.br

3 Instituto de Geociências, Universidade Federal da Bahia, Rua Barão de Jeremoabo, s/n, sala 315-C, Campus da Federação, 40170-115 Salvador, Bahia, Brasil. Tel: (71) 3203-8533; Fax: (71) 3203-8501 - End. elet.: johildo@cpgg.ufba.br 


\section{INTRODUÇ̃̃̃O}

Em escala de tempo geológica, apenas três elementos, em particular, quatro radioisótopos, $\mathrm{U}^{238}, \mathrm{U}^{235} \mathrm{e} \mathrm{Th}^{232} \mathrm{e} \mathrm{K}^{40}$, ocorrem em abundância suficiente para contribuir para 0 orçamento térmico da litosfera; estes elementos são referidos como elementos produtores de calor. Mais que 98\% do calor gerado no interior da Terra devem-se à radioatividade produzida pelos radioisótopos das séries naturais do $\mathrm{U}^{238}, \mathrm{U}^{235}$ e $\mathrm{Th}^{232}$ e pelo $\mathrm{K}^{40}$, sendo este calor radiogênico importante na definição do regime térmico da crosta terrestre. Numa bacia, parcelas do calor radiogênico produzido pelas rochas do embasamento, pelas camadas sedimentares da própria bacia (este menos importante), somado ao calor proveniente da astenosfera, desempenham papéis importantes em sua história térmica.

Para a prospecção de petróleo duma bacia, o conhecimento de sua história térmica é importante, pois dará indicações se esta foi capaz de gerar hidrocarbonetos. Nas bacias de Camamu e Almada, onde atualmente várias empresas de petróleo realizam trabalhos de prospecção de hidrocarbonetos em diferentes blocos de suas áreas imersas - com resultados positivos, principalmente na bacia de Camamu -, é importante conhecer-se nelas a distribuição dos elementos produtores de calor e a contribuição do calor radiogênico.

A formação e a origem da crosta terrestre são consideradas os principais fatores atuantes no transporte de materiais enriquecidos em urânio, tório e potássio. Esta mobilização ocorre através da atuação dos processos metamórficos, de fusão crustal, metassomatismo e migração de fluidos. A distribuição destes elementos nas várias litologias está diretamente ligada a estes processos, que normalmente ocorrem em diferentes profundidades na crosta terrestre e com variação na escala do tempo. A diferenciação magmática é responsável pela distribuição inicial de $\mathrm{K}$, U e Th, sendo os dois últimos mais sensíveis aos vários processos dessa diferenciação (Adams \& Gasparini, 1970). Posteriormente, a atuação dos processos metamórficos altera a distribuição destes elementos enriquecendo alguns de seus níveis. Do mesmo modo, a circulação das águas em grandes profundidades tende a redistribuir estes elementos, trazendo-os para as porções mais externas da crosta.

Os elementos K, U e Th estão presentes nas rochas em certos minerais e os teores desses elementos, nas diversas litologias, podem fornecer dados adicionais sobre as características químicas das rochas. Rochas de composição mineralógica caracterizada essencialmente por quartzo e plagioclásio apresentam baixas concentrações de K, U e Th, enquanto que as rochas com- postas por micas, feldspatos e minerais acessórios como o zircão, a apatita e a monazita, contêm teores maiores desses elementos. Há, assim, um crescimento dos teores de K, U e Th com o aumento do teor de sílica na rocha, com as rochas félsicas apresentando valores mais elevados do que as das rochas básicas.

A área de enfoque deste trabalho situa-se na porção leste do estado da Bahia, a qual é limitada ao norte pelo paralelo $13^{\circ} 30^{\prime} \mathrm{S}$, ao sul pela BR-415, a oeste pela BR-101 e a leste pelo oceano Atlântico. Na borda leste, situam-se as bacias sedimentares de Camamu e Almada, ocupando uma área total de $22.900 \mathrm{~km}^{2}$ até 0 limite da cota batimétrica de $3000 \mathrm{~m}$. Elas abrangem parte da planície costeira, limitando-se ao norte, através da falha de Itapuã, com a sub-bacia do Jacuípe e através da falha da Barra com a bacia do Recôncavo; ao sul limita-se com a bacia de Jequitinhonha, através do alto de Olivença. Com uma área de cerca de $10.000 \mathrm{~km}^{2}$, sendo $2.000 \mathrm{~km}^{2}$ emersas, a bacia de Camamu separa-se da bacia de Almada, pelo Alto de Itacaré (Gonçalves et al., 2000). 0 embasamento nesta área é conhecido pelos vários afloramentos de rochas cristalinas existentes. Segundo Barbosa (1986), estas rochas estão inseridas no contexto da região granulítica do sudeste da Bahia. Entre trabalhos anteriores descrevendo essas rochas, podemos citar os de Cordani (1973), Pedreira et al. (1975), Sighinolfi \& Sakai (1977), Costa \& Mascarenhas (1982) e Miranda et al. (1985), sendo que poucos deles se basearam em estudos petroquímicos. Trabalhos mais recentes (Barbosa 1986, 1989; Barbosa \& Fonteilles, 1991; Barbosa et al., 1998; Barbosa \& Sabaté, 2002, 2003) usando dados petroquímicos melhoraram, não somente o conhecimento das rochas da região, mas, também, evidenciou as principais feições tectônicas e metamórficas a elas associadas. Os litotipos do embasamento são representados por granulitos heterogêneos (rochas orto- e pára-derivadas), rochas chanockíticas, charnoenderbíticas, enderbíticas e gabro-anortosíticas do bloco Jequié, rochas orto- e pára-gnaíssicas associadas a anfibolitos da banda de Ipiaú e os metatonalitos associados a metagabros e os metamonzonitos do da parte sul do bloco Itabuna-Salvador-Curaçá.

Neste trabalho, apresentamos os resultados dos teores dos elementos K, U e Th e da taxa de produção de calor radiogênico determinados nos vários tipos de rochas do embasamento adjacente às bacias de Camamu e Almada.

\section{PRINCIPAIS LITOLOGIAS DO EMBASAMENTO}

0 embasamento cristalino no qual se situam as bacias de $\mathrm{Ca}$ mamu e Almada faz parte do Cráton do São Francisco (Almeida, 1977), mais precisamente, da Região Granulítica do Sudeste da 
Bahia (Barbosa, 1986). Esta última é caracterizada pelas unidades geotectônicas denominadas de Bloco Jequié, Banda de Ipiaú e Bloco Itabuna-Salvador-Curacá pertencentes ao Orógeno Itabuna-Salvador-Curaçá (Barbosa \& Sabaté, 2002; 2003). Estas unidades são compostas por um conjunto de rochas metamórficas da facies granulito e, subordinadamente, da facies anfibolito, apresentando idades arqueanas e paleoproterozóicas. A Figura 1 apresenta o mapa geológico simplificado das principais unidades geotectônicas deste embasamento.

As bacias de Camamu e Almada estão situadas sobre o Bloco Itabuna-Salvador-Curaçá (Fig. 1) e seu embasamento é formado, basicamente, por granulitos metatonalíticos, níveis de granulitos básicos deformados e granulitos metamonzoníticos. Mais distante das bacias, são encontrados os granulitos enderbíticos e charnockíticos (Bloco Jequié), o granito de Teolândia, o granodiorito de Moenda tendo como encaixantes gnaisses quartzofeldspáticos e anfibolitos (Banda de Ipiaú), além dos sienitos e dos diques máficos (Arcanjo et al., 1997; Sapucaia, 2004). A Figura 2 apresenta as principais unidades litológicas do embasamento das bacias, que serão descritas sucintamente a seguir.

\section{Granulitos tonalíticos e trondhjemíticos}

Estas rochas são as que se apresentam em maior proporção na área de estudo, estando deformadas e metamorfizadas na facies granulito. Quando inalteradas, estas rochas exibem coloração verde acinzentada, são medianamente homogêneas, exibindo, de uma maneira geral, granulação média a grossa. Mostram foliações com atitudes em torno de $\mathrm{N} 15^{\circ} \mathrm{E}$ e mergulhos subverticais. Mineralogicamente, elas são compostas de plagioclásio $(70-80 \%)$ e quartzo ( $<10 \%)$; em algumas amostras, são ainda encontradas pequenas porcentagens de piroxênio (hiperstênio), clinopiroxênio e feldspato potássico.

Com relação à petroquímica, utilizando preferencialmente os elementos terras-raras, as rochas em foco podem ser separadas em quatro principais tipos de metatonalitos, denominadas aqui de TT1, TT2, TT5 e TT6 (Barbosa et al., 2003), conforme indicados na Figura 3. Por sua vez, o diagrama normativo An-Ab-Or de O'Connor (1965) (Fig. 4) corrobora a classificação dessas rochas como tonalitos ou trondhjemitos metamorfizados em alto grau, sobretudo os granulitos tonalíticos, permitindo visualizar que a maioria das amostras situa-se no campo dos tonalitos embora algumas se encontrem no campo dos trondhjemitos.

\section{Granulitos básicos}

Dentro dos granulitos tonalíticos/trondhjemiticos, ocorrem os granulitos básicos sob a forma de bandas paralelas à foliação da rocha, com espessuras variando de centimétricas a métricas. Eles são formados por plagioclásio, ortopiroxênio (hiperstênio) e clinopiroxênio, em proporções relativamente próximas (40-50\%).

Os dados geoquímicos destes granulitos, quando lançados no gráfico de Le Maitre (1989) (Fig. 5), permitem classificá-los como provenientes do metamorfismo em basaltos e basaltos andesíticos. Com relação aos elementos terras-raras, os granulitos básicos apresentam um padrão relativamente plano, demonstrando uma filiação toléíica (Fig. 6) (Barbosa et al., 2003).

\section{Metamonzonitos shoshoníticos}

Arcanjo et al. (1992) definiu os corpos de rochas intrusivas do embasamento das bacias sedimentares de Camamu e Almada que exibem filiação química shoshonítica como monzonitos e quartzo-monzodioritos, que foram deformados e reequilibrados na facies granulito, como indicado no diagrama normativo/modal QAP de Streickeisen (1975) apresentado na Fig. 7. Mineralogicamente, estas rochas são constituídas de mesopertita (20\%), ortopiroxênio (15\%), clinopiroxênio (15\%), plagioclásio andesítico (30\%), biotita (15 a 20\%) e acessórios como, quartzo, opacos, apatita e zircão (Barbosa et al., 2003; Sapucaia, 2004).

\section{Granulitos charnockiticos, charnoenderbiticos e enderbiticos}

Definidos por Barbosa (1986) e Fornari \& Barbosa (1992), os granulitos charnockiticos, charnoenderbiticos e enderbiticos ocorrem na parte noroeste da área em foco (Fig. 2). Elas são rochas originalmente plutônicas, exibindo textura grossa e constituídas por cristais de mesopertita (40 a 50\% nos casos dos granulitos charnockitos, e 15 a $20 \%$ para os charnoenderbíticos) e de plagioclásio $(60 \%)$. Para os enderbitos, os cristais de plagioclásio antipertítico estão envolvidos por uma matriz de quartzo (5-10\%) e ortopiroxênio (2-5\%), este, por vezes, alternando com o clinopiroxênio, hornblenda marrom e biotita.

0 diagrama de Streickeisen (1975) confirma a classificação dessas rochas como charnockíticas, charnoenderbíticas e enderbíticas (Fig. 7).

\section{Granito de Teolândia, granodiorito Moenda e anfibolitos da Banda de Ipiaú}

0 granito de Teolândia e o granodiorito Moenda, juntamente com os anfibolitos, ocorrem na Banda de Ipiaú (Fig. 2), cuja característica principal é que suas litologias estão equilibradas na 


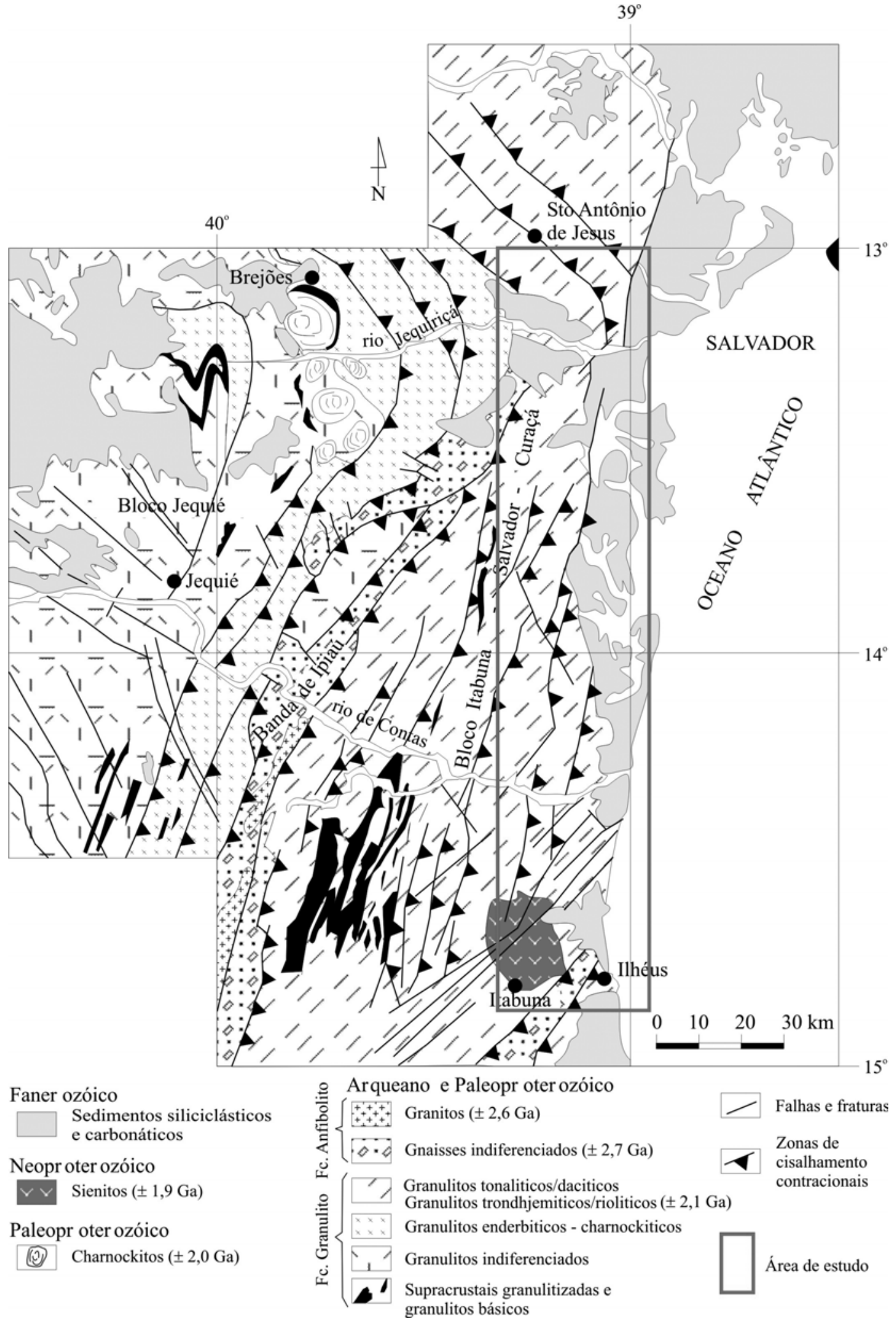

Figura 1 - Mapa geológico simplificado da região granulítica do sudeste da Bahia, com indicação da área de trabalho. Modificado de Barbosa et al., 2004. 


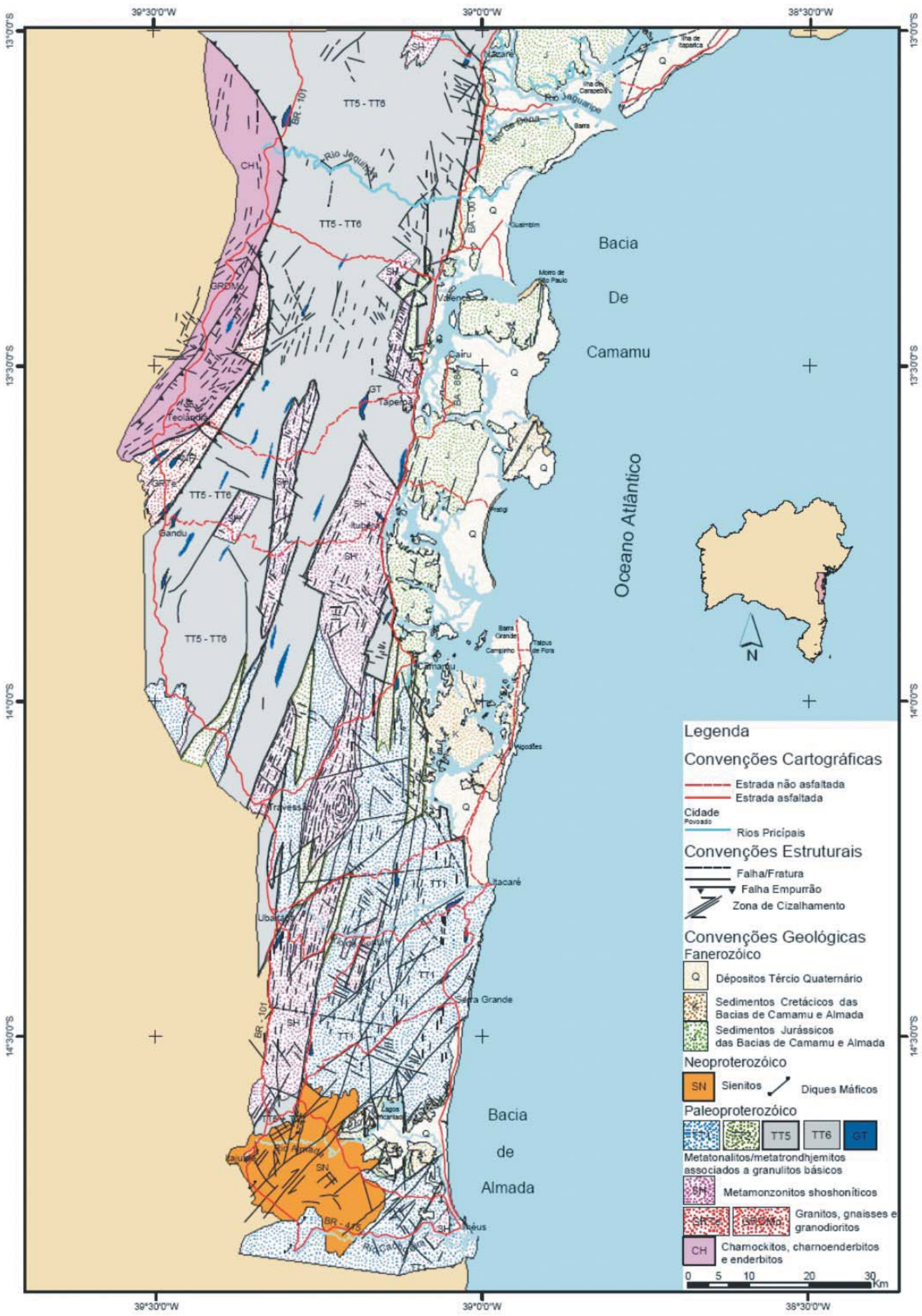

Figura 2 - Mapa geológico do embasamento adjacente às bacias de Camamu e Almada de acordo com Sapucaia (2004). 


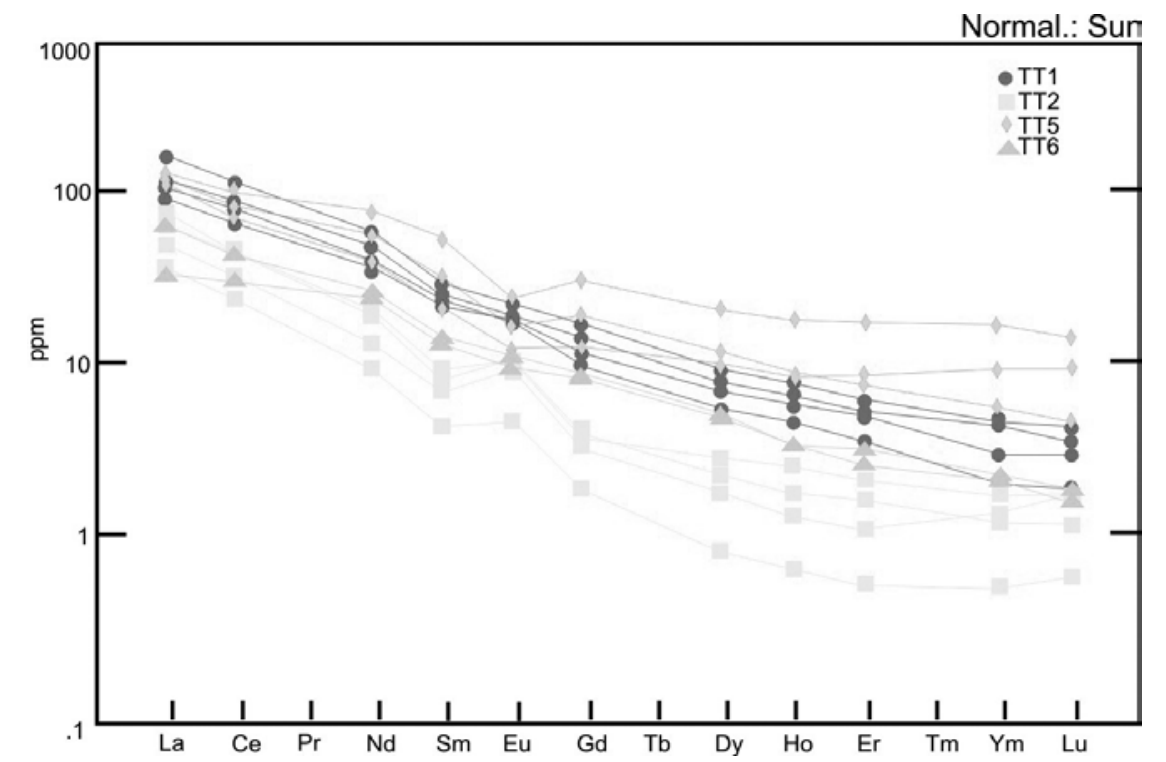

Figura 3 - Espectro dos elementos terras-raras dos granulitos metatonalíticos TT1, TT2, TT5 e TT6, mostrando um padrão geral cálcio-alcalino de baixo potássio.

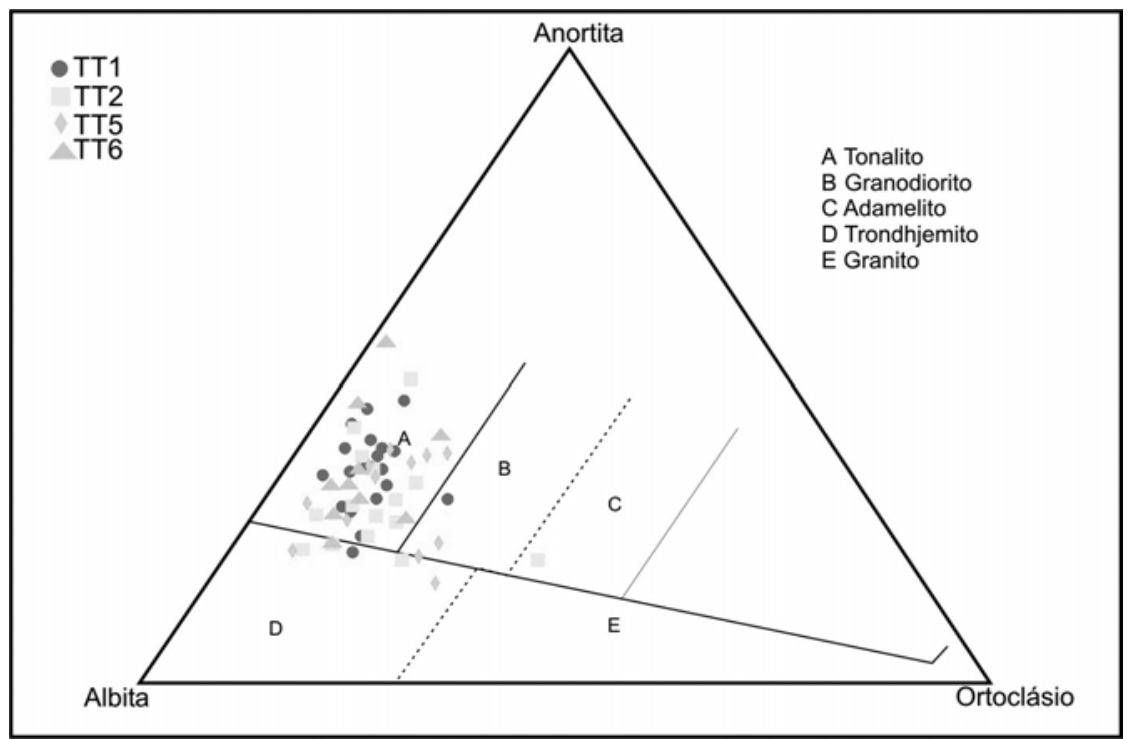

Figura 4 - Diagrama normativo de An-Ab-Or (0'Connor, 1965), mostrando que a maioria dos pontos representativos dos granulitos tonalíticos e trondhjemíticos estudados situam-se no campo dos tonalitos e trondhjemitos.

facies anfibolito. Os granitos e granodioritos apresentam, no campo, cor rósea e granulometria grossa, onde os cristais de microclina e/ou feldspato pertítico encontram-se envolvidos por uma matriz mais fina. Quanto à moda, essas rochas são compostas por quartzo, plagioclásio, microclina, hornblenda, biotita e opacos. 0 diagrama de Streickeisen (1975) apresentado na Figura 7, por sua vez, possibilita mostrar, através de analises químicas, que estes corpos plutônicos são formados de granitos e granodioritos.

Intercalada aos granitos e granodioritos da Banda de Ipiaú, ocorrem níveis de anfibolitos. Estes exibem coloração preta a esverdeada, com textura granular média. Os cristais de hornblenda dessas rochas encontram-se orientados segundo a foliação regional. 


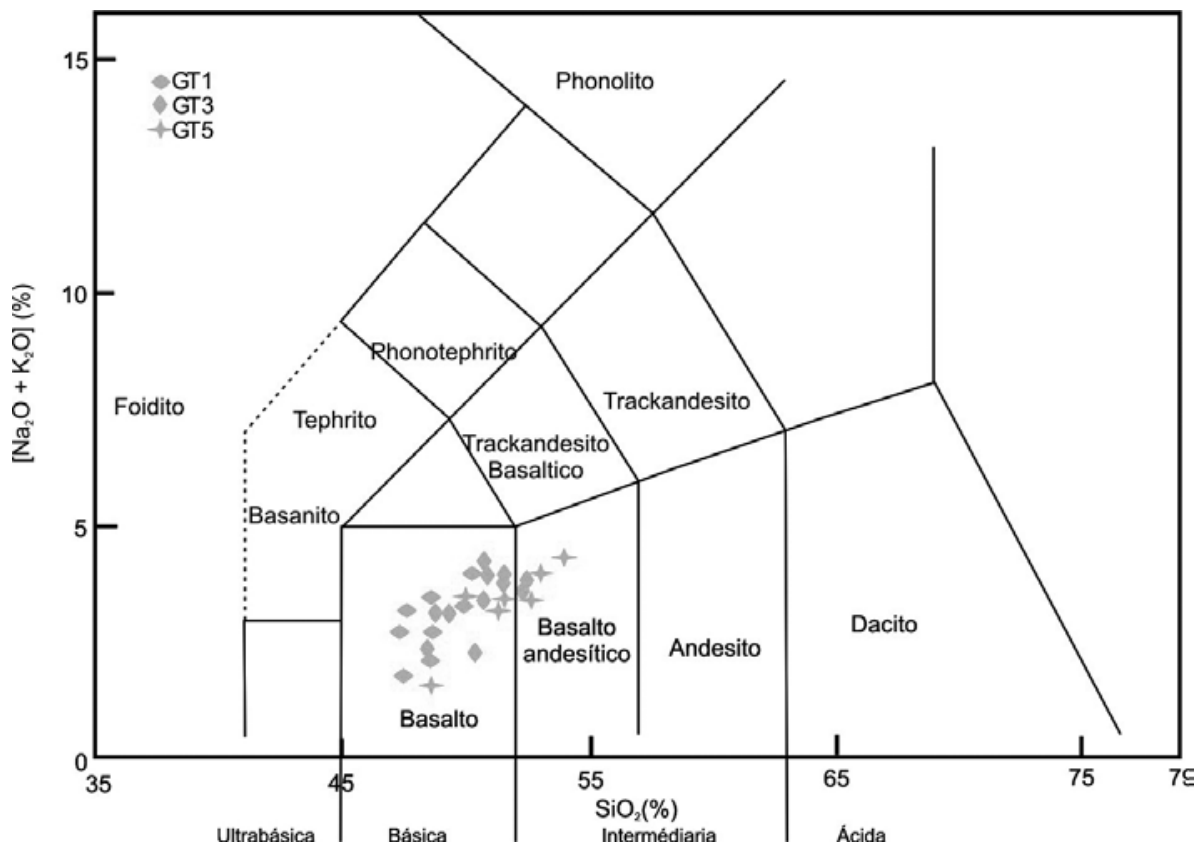

Figura 5 - Diagrama de Le Maitre (1989), classificando os granulitos básicos como provenientes do metamorfismo em basaltos e basaltos andesíticos.

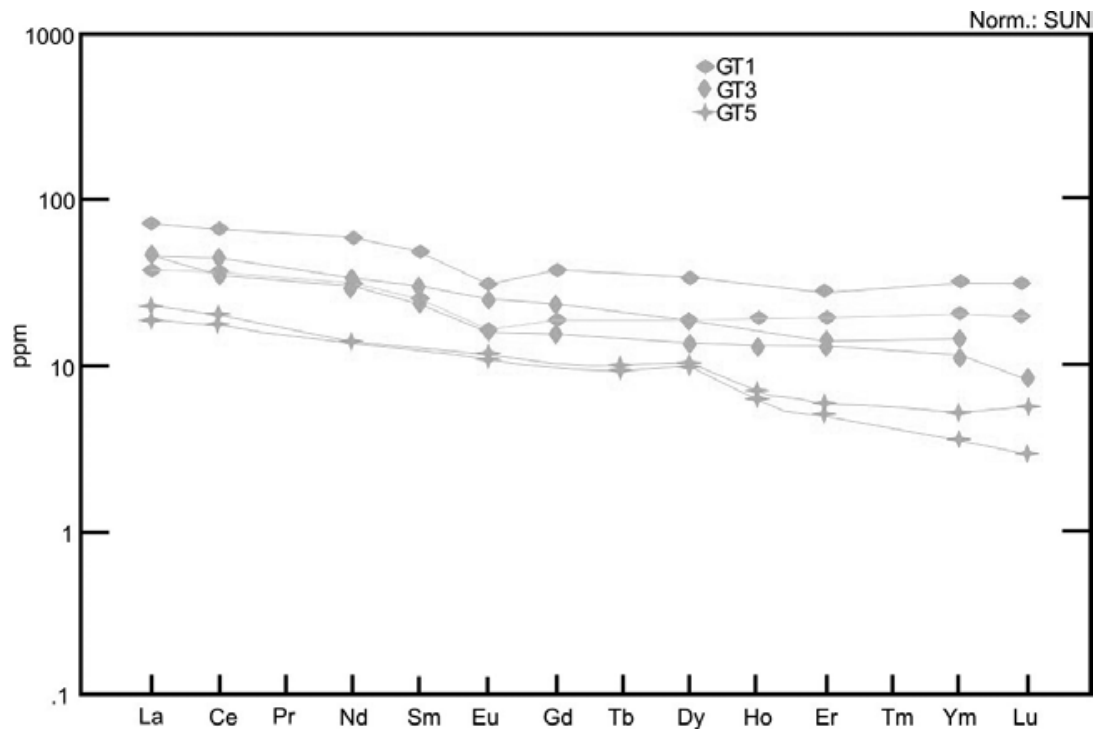

Figura 6 - Espectro dos elementos terras-raras dos granulitos básicos GT1, GT3 e GT5.

\section{Sienitos e os diques máficos neoproterozóicos}

Os sienitos neoproterozóicos fazem parte do grupo de rochas definido por Arcanjo et al. (1997) como Suíte Intrusiva de Itabuna. Segundo aqueles autores, estudos geocronológicos mostram, através de diagramas isocrônicos $\mathrm{Rb} / \mathrm{Sr}$ (rocha total), que estas litologias apresentam idades de $660 \pm 9,8$ Ma. Esta suíte é formada por rochas de composição sienítica, com alguns diferenciados básicos. No geral, são rochas homogêneas, com granulometria fanerítica grossa e coloração cinza clara a cinza escura. A mineralogia predominante para os sienitos é 0 feldspato potássico (84\%), hornblenda (5\%) e opacos. Já os monzodioritos são formados por plagioclásio (46\%), feldspato potássico (24\%), hornblenda (13\%), biotita (2\%), clinopiroxênio (12\%) e 


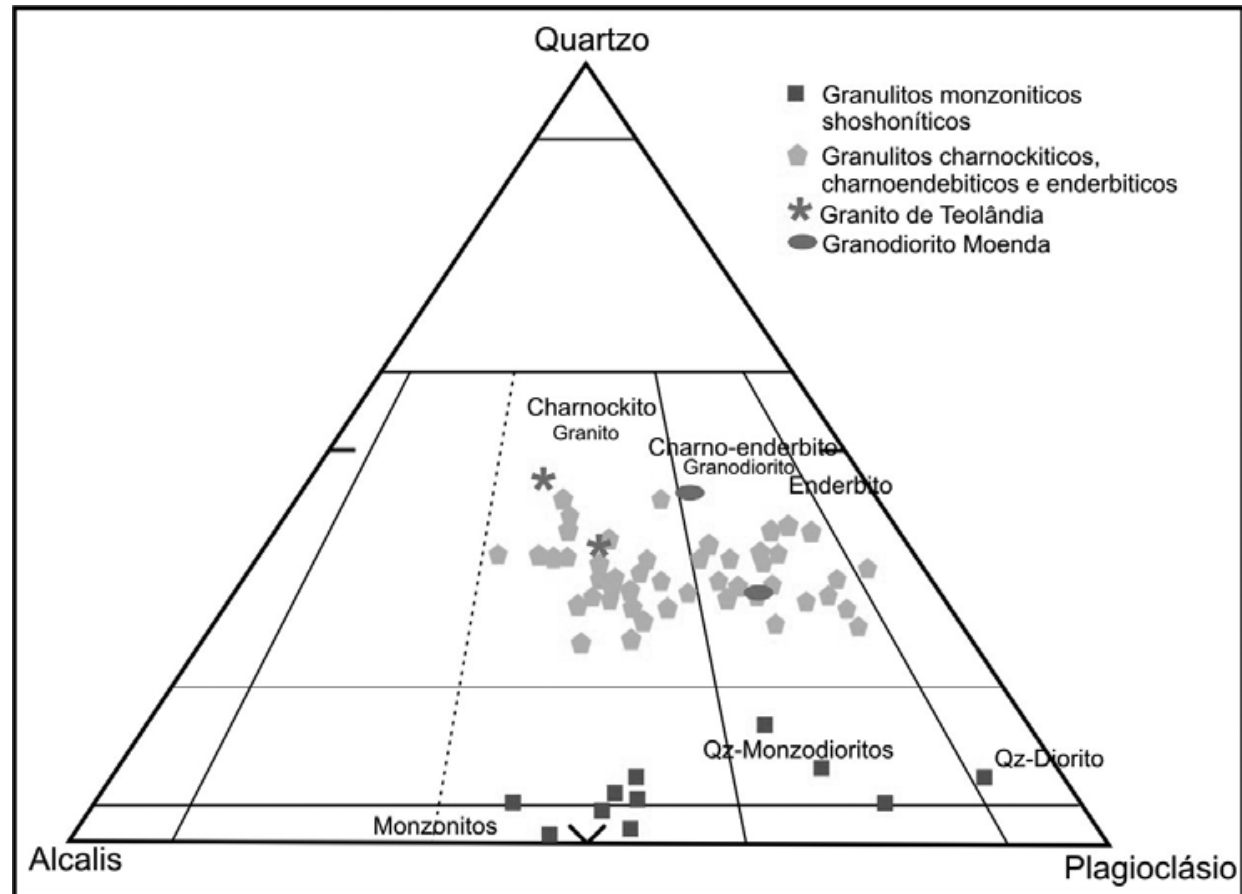

Figura 7 - Diagrama normativo/modal QAP situando os granulitos metamonzoníticos, charnockíticos, charnoenderbíticos e enderbíticos, o granito de Teolândia e o granodiorito de Moenda, nos campos característicos definidos por Streickeisen (1975).

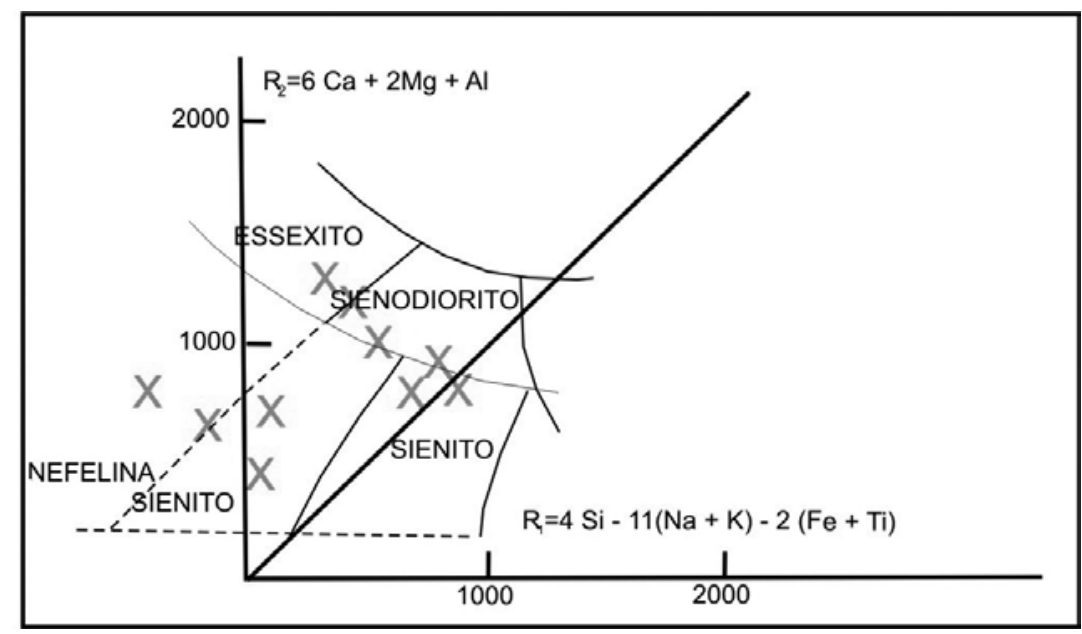

Figura 8 - Diagrama multicatiônico R1-R2 (La Roche et al., 1980) mostrando que os sienitos neoproterozóicos apresentam caracteres essexítico, sienodiorítico e nefelina-sienítico.

opacos. Geoquimicamente, os sienitos da suíte intrusiva de ltabuna são classificados como essexitos, sieno - dioritos e nefelina sienitos como mostra o diagrama multicatiônico R1-R2 (La Roche et al., 1980), apresentado na Figura 8.

Segundo Arcanjo et al. (1997), os diques máficos são encontrados de forma aleatória na área penetrando fraturas que atingi- ram as unidades litológicas que afloram na parte sul do embasamento adjacente à bacia de Almada, constituindo um enxame de diques, os quais possuem espessuras variando de milimétricas a métricas. Esses diques máficos exibem uma coloração cinza escura, granulometria afanítica a fanerítica média e textura porfirítica a subofítica. Sua mineralogia é formada por plagioclásio (40\%), 
piroxênio (30\%), hornblenda (8\%), biotita (7\%) e opacos. Geoquimicamente, os diques máficos da área estudada apresentam duas filiações distintas, permitindo classificá-los como basaltos alcalinos e basaltos toléiticos.

\section{METODOLOGIA}

\section{Amostragem}

Fizemos as medidas de campo e coleta de amostras sobre afloramentos rochosos localizados próximos às estradas e caminhos existentes na região das bacias de Camamu e Almada e numa faixa de $60 \mathrm{~km}$ das bordas emersas dessas bacias. Procuramos atingir todos os afloramentos nesta faixa amostrando os pontos a cada $3 \mathrm{~km}$ em média, ou em intervalos menores quando se verificava mudança de litologia ou nos teores dos elementos K, U e Th.

No total, visitamos 182 afloramentos de rochas cristalinas e coletadas 181 amostras, algumas vezes mais de uma por afloramento, outras vezes nenhuma amostra quando as rochas apresentavam-se alteradas. Em cada afloramento, determinamos sua localização por GPS, medimos os teores de K, U e Th utilizando um espectrômetro gama portátil GS-512 da Geofisika equipado com um detector de cintilação de INa(TI) de $76 \times 76 \mathrm{~mm}$ e coletamos de 2 a $3 \mathrm{~kg}$ de rocha sã para determinação de seus teores de K, U e Th em laboratório e de sua densidade.

\section{Procedimentos para medida dos teores de potássio, urânio e tório}

Determinamos os teores de potássio, urânio e tório nas amostras de rocha no laboratório por espectrometria gama. Esta é uma técnica bem estabelecida e descrita por vários autores (Adams \& Gasparini, 1970; Rybach, 1988; Alves Júnior, 2004; Sapucaia, 2004), na qual se assume a razão isotópica $\mathrm{K}^{40} / \mathrm{K}_{\text {total }}$ constante e igual a 0,01167\% e equilíbrio secular das séries do $\mathrm{U}^{238} \mathrm{e} \mathrm{Th}^{232}$. Neste trabalho, utilizamos dois espectrômetros, ambos com detectores de cintilação de $\mathrm{INa}(\mathrm{TI})$ da Harshaw com $102 \mathrm{~mm}$ de diâmetro e $76 \mathrm{~mm}$ de altura montados no interior de castelos independentes, ambos com dimensões internas de $73 \times 86 \times 73 \mathrm{~cm}$, paredes de $12 \mathrm{~cm}$ de chumbo e $0,5 \mathrm{~cm}$ de cobre (internamente) e instalados numa sala subterrânea climatizada. Para esses dois espectrômetros (referidos como 3 e 4), as resoluções são de 10,0 e 10,5\% para o pico de $662 \mathrm{keV}$ do $\mathrm{Cs}^{137}$ e de 4,6 e 4,7\% para 0 pico de $2.614 \mathrm{keV}$ do $T \mathrm{~T}^{208}$. 0 programa para obtenção dos espectros e tratamento de dados é o MAESTRO A65-B32, versão 5.34 da Ortec.

As amostras para contagem gama foram preparadas moendose cerca de $1,5 \mathrm{~kg}$ de rocha para uma mesma granulometria (areia fina) e alíquotas de cerca de $900 \mathrm{~g}$ de material homogeneizado foram acondicionadas em potes plásticos de $125 \times 40 \mathrm{~mm}$ enchendo-os totalmente. As densidades das amostras acondicionadas nos potes variaram em menos de $15 \%$ em relação àquelas dos padrões, o que faz desprezível os efeitos de atenuação por diferenças de densidade para as radiações utilizadas em nosso método, todas acima de 880 keV (Ketcham, 1996; Hasan et al., 2002). Usamos tempo de contagem de $30.000 \mathrm{~s}$ e 0 ruído de fundo utilizado foi integrado em $90.000 \mathrm{~s}$. 0 controle da deriva dos espectros foi realizado a cada inicio de contagem de uma nova amostra ajustando a posiçãa do fotopico de $662 \mathrm{keV} \mathrm{do} \mathrm{Cs}^{137}$ no canal 182 para ambos os detectores - nas condições de nosso laboratório as derivas ficaram em torno de 1 canal.

Os teores de potássio, urânio e tório foram determinados usando o método descrito por Sapucaia (2004). Neste método, o espectro gama obtido na contagem da amostra, depois de subtraído o ruído de fundo, é assumido consistir apenas das contribuições dos elementos $\mathrm{K}, \mathrm{U}$ e Th, presentes na amostra. Neste espectro, define-se três janelas espectrais de tal modo que a janela 1 inclui 0 fotopico de $1461 \mathrm{keV}$ do $\mathrm{K}^{40}$, a janela 2 inclui o fotopico de $1764 \mathrm{keV}$ do $\mathrm{Bi}^{214}$ e a janela 3 inclui o fotopico de $2614 \mathrm{keV}$ do $\mathrm{Tl}^{208}$ (ver Tab. 1). Deste modo, a massa $S_{\mathrm{N}}$ do elemento $S$ na amostra $N$ pode ser obtida pela expressão

$$
S_{N}=\sum m_{i j} A_{j N},
$$

onde $i$ representa 0 elemento químico $(K=1, U=2 \mathrm{e}$ $T h=3), j$ indica as janelas (1, 2 e 3), $A_{j, N}$ são as taxas de contagem da amostra $N$ na janela $j$ (subtraído o ruído de fundo) e $m_{i j}$ são coeficientes a determinar. $S$ é 0 símbolo do elemento químico (K, $U$ e Th) e representa sua massa.

As massas dos três elementos na amostra são, então, escritas como

$$
\begin{aligned}
K_{N} & =\sum_{j=1}^{3} m_{l j} A_{j N} \\
U_{N} & =\sum_{j=1}^{3} m_{2 j} A_{j N} \\
T h_{N} & =\sum_{j=1}^{3} m_{3 j} A_{j N}
\end{aligned}
$$

Os nove coeficientes $m_{i j}$ são determinados utilizando três padrões ( $N=1,2$ e 3 ) nos quais as massas de potássio, urânio e tório são conhecidas - todos contados sob a mesma geometria experimental $-\mathrm{e}$ as atividades $A_{j, N}$ (subtraído o ruído de fundo) nas janelas medidas. 
Conhecidos os coeficientes $m_{i j}$, as concentrações na amostra de potássio $C_{K}$ (em \%), do urânio $C_{U}$ (em ppm) e do tório $C_{T h}$ (em ppm) são obtidas pelas equações

$$
\begin{aligned}
C_{K} & =\frac{10^{2}}{M t}\left(m_{11} J_{1}+m_{12} J_{2}+m_{13} J_{3}\right) \\
C_{U} & =\frac{10^{6}}{M t}\left(m_{21} J_{1}+m_{22} J_{2}+m_{23} J_{3}\right) \\
C_{T h} & =\frac{10^{6}}{M t}\left(m_{31} J_{1}+m_{32} J_{2}+m_{33} J_{3}\right)
\end{aligned}
$$

onde $M$ é a massa da amostra, $t$ é 0 tempo de contagem e $J_{1}, J_{2}$ e $J_{3}$ são as contagens no tempo $t$ (subtraído o ruído de fundo) nas janelas espectrais $1,2 \mathrm{e} 3$, respectivamente. É importante enfatizar que estas equações só são válidas se as amostras forem contadas na mesma geometria em que foram contados os padrões.

Na Tabela 2 apresentamos as composições dos três padrões utilizados na calibração absoluta do espectrômetro no laboratório com a indicação das massas e das concentrações dos elementos K, U e Th. Preparamos estes padrões diluindo alíquotas dos padrões RGK-1, RGU-1 e RGTh-1 fornecidos pela AIEA numa matriz de quartzito com teores desprezíveis de $\mathrm{K}$, U e Th.

Neste trabalho, o nível crítico, obtivemos o limite de detecção e 0 limite de determinação segundo Currie (1968). 0 ruído de fundo utilizado foi integrado em $25 \mathrm{~h}$, tomamos $\alpha=\beta=0,05$ $(k=1,645)$ e um desvio padrão relativo máximo permitido desejável de $10 \%\left(k_{Q}=10\right)$ nas atividades líquidas de todas as janelas. Nas Tabelas 3 e 4 mostramos os valores do ruído de fundo, do nível crítico e dos limites de deteç̧ão e de determinaçãa, em contagem por hora (cph) nas três janelas dos 3 e 4 .

Os limites médios de determinação quantitativa do laboratório, expressos em concentrações, foram obtidos comparandose as contagens líquidas médias dos limites de determinações com as contagens líquidas dos padrões nas respectivas janelas. Estes limites são, para ambos os espectrômetros, de 0,02\% para o K, 0,2 ppm para o U e 0,4 ppm para o tório.

Para verificar a coerência dos resultados das concentrações obtidas nos espectrômetros 3 e 4, medimos 7 amostras com concentrações variadas em ambos os detectores e os resultados apresentaram discrepâncias relativas de 1,6\% para o K, 4,6\% para o U e 2,4\% para 0 Th. Avaliamos a precisão do método, medindo seis alíquotas de um mesmo arenito com concentrações de 1,7\% para K, 1,8 ppm para U e 9,7 ppm para Th: 0 desvio relativo médio para os dois detectores foi de $1,6 \%$ para $0 \mathrm{~K}, 4,6 \%$ para $0 \mathrm{U}$ e $2,4 \%$ para 0 Th. Assumimos equilíbrio secular para as amostras, considerando terem as formações idades superiores a $1 \mathrm{Ga}$ e algumas delas terem sido datadas. Para remediar possíveis perdas do urânio, procuramos amostrar rochas frescas e, como $0 \mathrm{Ra}^{222}$ pode escapar da rocha que seja fraturada ou desagregada, os potes com as amostras moídas foram lacrados com silicone e guardados por um mínimo de três semanas antes de serem medidos já que 0 equilíbrio refaz-se em três semanas.

A taxa de produção volumétrica de calor radiogênico (A), expressa em $\mu \mathrm{W} \mathrm{m}^{-3}$, foi calculada usando a expressão devida a Rybach (1988),

$$
A=10^{-5} \rho\left(3,48 C_{K}+9,52 C_{U}+2,56 C_{T h}\right),
$$

onde, $C_{K}$ é 0 teor de potássio na amostra dado em porcentagem, $C_{U}$ e $C_{T h}$ são os teores de urânio e tório, respectivamente, em ppm e $\rho$ é a densidade da rocha em $\mathrm{kg} \mathrm{m}^{-3}$.

As densidades absolutas das rochas foram medidas usandose um ultrapicnômetro de QuantaCHROME, modelo 1000, em amostras com cerca de $50 \mathrm{~cm}^{3}$.

\section{RESULTADOS E DISCUSSÃO}

Nas 205 amostras coletadas, determinamos no laboratório os teores de $\mathrm{K}, \mathrm{U}$ e Th e as densidades de todas elas. Os granulitos metatonalíticos participaram em maior proporção com 94 amostras - esta litologia apresentou maior número de afloramentos - os granulitos metamonzoníticos e os granulitos básicos tiveram cerca de 30 amostras cada uma, os granulitos charnockíticos e sienitos neoproterozóicos participaram com 12 e 16 amostras, respectivamente, as rochas da Banda de Ipiaú contribuíram com 6 amostras e 0 anfibolito e dique máfico tiveram uma amostra cada. Na Tabela 5 apresentamos as faixas de concentrações de $\mathrm{K}$, U e Th, as densidades e a faixa de taxa de produção volumétrica de calor radiogênico obtidas para as principais unidades litológicas do embasamento adjacente às bacias de Camamu e Almada. Nesta tabela, observa-se que os granulitos charnockíticos e metamonzoníticos, o granito de Teolândia, 0 granodiorito de Moenda e 0 sienito (neoproterozoico), são as rochas com os teores mais elevados de K, U e Th. Corroborando com suas mineralogias, os granulitos metatonalíticos apresentam teores intermediários destes elementos, enquanto os granulitos básicos apresentam teores baixos.

Na Figura 9 mostramos as correlações entre os teores dos elementos U e K, Th e K e U e Th. Vê-se nesta figura que teores altos de $\mathrm{U}$ e Th estão relacionados com teores também altos de K, não sendo 0 inverso verdadeiro, pois aparecem altos teores de $K$ associados a baixos teores de $U$ e Th. Situação semelhante ocorre com a correlação entre o U e Th (Fig. 9) onde teores altos de U correspondem a teores também altos de Th, mas há valores altos de Th associados a teres baixos de $U$. 
Tabela 1 - Janelas espectrais que incluem os fotopicos do $\mathrm{K}^{40}, \mathrm{Bi}^{214}$ e Tl${ }^{208}$ para os dois espectrômetros gama.

\begin{tabular}{|c|c|c|c|c|}
\hline \multirow{2}{*}{ Janela espectral } & \multicolumn{2}{|c|}{ Faixa de energia da janela (keV) } & \multirow{2}{*}{ Energia do fotopico principal (keV) } & Isótopo \\
\cline { 2 - 3 } & Espectrômetro 3 & Espectrômetro 4 & & $\mathrm{K}^{40}$ \\
\hline Janela 1 & 887,3 a 1614 & 878,2 a 1614 & 1461 & $\mathrm{Bi}^{214}$ \\
\hline Janela 2 & 1636 a 2039 & 1636 a 2039 & 1764 & $\mathrm{Tl}^{208}$ \\
\hline Janela 3 & 2061 a 2814 & 2062 a 2814 & 2614 & \\
\hline
\end{tabular}

Tabela 2 - Massa e teores de K, U e Th nos padrões.

\begin{tabular}{|c|c|c|c|c|}
\hline Padrão & $\begin{array}{c}\text { Massa do padrão } \\
(\mathrm{g})\end{array}$ & $\begin{array}{c}\text { Teor de potássio } \\
(\%)\end{array}$ & $\begin{array}{c}\text { Teor de urânio } \\
(\mathrm{ppm})\end{array}$ & $\begin{array}{c}\text { Teor de tório } \\
(\mathrm{ppm})\end{array}$ \\
\hline 1 & 882,20 & 5,00 & 2,00 & 5,00 \\
\hline 2 & 836,53 & 0,500 & 15,00 & 5,00 \\
\hline 3 & 834,17 & 0,500 & 2,00 & 40,00 \\
\hline
\end{tabular}

Tabela 3 - Ruído de fundo médio, nível crítico e limites de detecção e de determinação, como definidos por Currier (1968), para o espectrômetro gama 3. Valores expressos em contagem/hora (cph).

\begin{tabular}{|c|c|c|c|c|}
\hline Espectrômetro 3 & $\begin{array}{c}\text { Ruído de fundo } \\
\text { (cph) }\end{array}$ & $\begin{array}{c}\text { Nível crítico } N_{C} \\
\text { (cph) }\end{array}$ & $\begin{array}{c}\text { Limite de detecção } L_{D} \\
(\text { cph })\end{array}$ & $\begin{array}{c}\text { Limite de determinação } L_{Q} \\
\text { (cph) }\end{array}$ \\
\hline Janela 1 & $2711 \pm 73$ & $17,30 \pm 0,46$ & $34,37 \pm 0,92$ & $106,2 \pm 2,9$ \\
\hline Janela 2 & $697 \pm 26$ & $8,68 \pm 0,32$ & $17,48 \pm 0,65$ & $54,8 \pm 2,0$ \\
\hline Janela 3 & $549 \pm 23$ & $8,43 \pm 0,35$ & $15,53 \pm 0,65$ & $48,9 \pm 2,0$ \\
\hline
\end{tabular}

Tabela 4 - Ruído de fundo médio, nível crítico e limites de detecção e de determinação, como definidos por Currier (1968), para espectrômetro gama 4. Valores expressos em contagem/hora (cph).

\begin{tabular}{|c|c|c|c|c|}
\hline Espectrômetro 4 & $\begin{array}{c}\text { Ruído de fundo } \\
\text { (cph) }\end{array}$ & $\begin{array}{c}\text { Nível crítico } N_{C} \\
\text { (cph) }\end{array}$ & $\begin{array}{c}\text { Limite de detecção } L_{D} \\
(\text { cph })\end{array}$ & $\begin{array}{c}\text { Limite de determinação } L_{Q} \\
\text { (cph) }\end{array}$ \\
\hline Janela 1 & $2743 \pm 52$ & $17,23 \pm 0,32$ & $34,57 \pm 0,66$ & $106,8 \pm 2,9$ \\
\hline Janela 2 & $512 \pm 25$ & $7,44 \pm 0,36$ & $15,00 \pm 0,73$ & $54,8 \pm 2,0$ \\
\hline Janela 3 & $488 \pm 18$ & $7,27 \pm 0,35$ & $14,64 \pm 0,54$ & $48,9 \pm 2,0$ \\
\hline
\end{tabular}

\section{Potássio}

As concentrações de $\mathrm{K}$ mostradas na Tabela 5 são relativamente mais elevadas nos granulitos charnockíticos, com uma média e intervalo de um desvio padrão de $3,51 \pm 0,72 \%$, de $3,2 \pm$ $1,1 \%$ nos granulitos metamonzoníticos, de 3,03 $\pm 0,48 \%$ no granito de Teolândia, de 2, $22 \pm 0,40 \%$ no granodiorito de Moenda e de 3, $27 \pm 0,92 \%$ no sienito neoproterozóico, corroborando com suas porcentagens altas de feldspatos potássicos (microclina, ortoclásio e mesopertita) os quais firmam o potássio como um elemento importante em sua estrutura cristalina. Igualmente corroborando com sua mineralogia, os granulitos metato- nalíticos apresentam teores intermediários de $\mathrm{K}$ variando de 0,21 a 4,33\%, constituindo-se em dois grupos, como se observa na Figura 10, onde se apresenta a dispersão dos teores de K nas principais unidades litológicas da área estudada. 0 grupo predominante tem média de $0,88 \pm 0,35 \%$ e 0 outro, com 19 amostras, tem média de 2, $24 \pm 0,64 \%$. Os granulitos básicos, por sua vez, apresentam teores baixos de $\mathrm{K}$, situados entre 0,02 a 0,88\% com valor médio de 0, $39 \pm 0,19 \%$. Na Figura 11 salientamos os teores de potássio através do mapa de isoteores da área, ressaltando as unidades litológicas que apresentam teores elevados, como as rochas indicadas anteriormente e observadas no mapa geológico (Fig. 2). 
Tabela 5 - Intervalo de variação dos teores de potássio, urânio e tório, das taxas de produção volumétrica de calor radiogênico, e densidades para as principais unidades litológicas do embasamento adjacente às bacias de Camamu e Almada. Legenda: n.d. - valores não detectados.

\begin{tabular}{|c|c|c|c|c|c|c|}
\hline \multirow[b]{2}{*}{ Unidades litológicas } & \multirow[b]{2}{*}{$\mathrm{N}^{0}$ de amostras } & \multicolumn{3}{|c|}{ Teores } & \multirow[b]{2}{*}{$\begin{array}{c}\text { Densidade } \\
\left(10^{3} \mathrm{~kg} \mathrm{~m}^{-3}\right)\end{array}$} & \multirow[b]{2}{*}{$\begin{array}{l}\text { Calor radiogênico } \\
\qquad\left(\mu \mathrm{W} \mathrm{m}^{-3}\right)\end{array}$} \\
\hline & & $\begin{array}{c}\mathrm{K} \\
(\%)\end{array}$ & $\begin{array}{c}\mathrm{U} \\
(\mathrm{ppm})\end{array}$ & $\begin{array}{c}\text { Th } \\
\text { (ppm) }\end{array}$ & & \\
\hline Metatonalitos & 94 & 0,21 a 4,33 & n.d. a 3,03 & 0,54 a 11,46 & $2,83 \pm 0,11$ & 0,10 a 1,44 \\
\hline Granulitos básicos & 32 & 0,02 a 0,88 & n.d. a 0,58 & n.d. a 1,91 & $2,98 \pm 0,12$ & 0,06 a 0,36 \\
\hline Metamonzonitos & 29 & 1,37 a 6,33 & n.d. a 9,10 & n.d. a 37,37 & $2,824 \pm 0,086$ & 0,23 a 5,55 \\
\hline Charnockitos & 12 & 2,31 a 4,50 & 0,23 a 8,51 & 1,43 a 64,38 & $2,718 \pm 0,022$ & 1,26 a 5,57 \\
\hline $\begin{array}{l}\text { Granito de } \\
\text { Teolândia }\end{array}$ & 3 & 2,53 a 3,49 & 0,91 a 5,75 & 30,13 a 35,25 & $2,724 \pm 0,013$ & 2,62 a 4,21 \\
\hline $\begin{array}{l}\text { Granodiorito } \\
\text { de Moenda }\end{array}$ & 3 & $1,87-2,65$ & n.d. a 1,31 & 4,84 a 22,30 & $2,753 \pm 0,009$ & 0,58 a 2,09 \\
\hline Sienitos & 16 & $2,57-4,69$ & 0,52 a 3,78 & 0,56 a 14,14 & $2,802 \pm 0,085$ & 0,60 a 2,24 \\
\hline
\end{tabular}

\section{Urânio}

Na Tabela 5 apresentamos a faixa de valores e na Figura 12 mostramos a dispersão dos teores de urânio nas unidades litológicas do embasamento estudado. Os teores de urânio são relativamente mais altos nos granulitos charnockíticos com média de 1,52 \pm 0,76 ppm, nos sienitos com média de $1,38 \pm 0,97$ ppm, no granito de Teolândia onde varia de 0,91 a 5,75 ppm e no granodiorito de Moenda variando de não-detectável (n.d.) a 1,31 ppm. Os valores intermediários encontram-se nos granulitos metamonzoníticos com média de $0,38 \pm 0,23$ ppm e nos granulitos metatonalíticos com os teores variando entre n.d. e 3,03 ppm e com média de 0,37 $\pm 0,26 \mathrm{ppm}$. Os granulitos básicos têm um grupo de 19 amostras com teores na faixa não-detectada $(<0,2$ ppm) e outro grupo de 10 amostras com valor médio de $0,32 \pm 0,10 \mathrm{ppm}$. Teores elevados de $U$ de até 9,1 ppm são observados em algumas amostras de rochas granulíticas charnockíticas e metamonzoníticas. Esses teores são considerados anômalos e correspondem, também, a altas concentrações de potássio e tório, como mostrado na Figura 9, onde se evidenciam os teores mais altos nos granulitos charnockíticos e monzoníticos, no granito de Teolândia, no granodiorito de Moenda e no sienito Na Figura 13 mostramos o mapa de isoteores do urânio da área estudada onde as regiões de teores altos correspondem às litologias referidas acima.

\section{Tório}

Nas amostras analisadas, os teores de tório variam de $0,4 \mathrm{a}$ 36,58 ppm, mas teores tão altos como 64,38 ppm são encontrados nos granulitos charnockíticos (Tab. 6). Na Figura 14 mos- tramos a dispersão dos teores de tório nas litologias das áreas estudadas. Semelhante ao comportamento do urânio, os teores de tório são relativamente mais altos nos granulitos charnockíticos com média de $28 \pm 19$ ppm, nos sienitos com média de 6,7 \pm 4,0 ppm, no granito de Teolândia com média de 33, $3 \pm 2,8$ ppm e no granodiorito de Moenda onde varia de 4,84 a 22,30 ppm. Os valores intermediários encontram-se nos granulitos metamonzoníticos com média de 1,39 $\pm 0,94$ ppm e nos granulitos metatonalíticos onde distinguimos dois grupos limitados pelo teor de 1,5 ppm: um grupo tem teor médio de $0,80 \pm 0,68$ ppm e outro com 3, $6 \pm 2,8$ ppm. Os granulitos básicos têm a maioria das amostras na faixa não-detectada $(<0,4$ ppm) com uma média de 0,64 $\pm 0,36$ ppm.

Na Figura 15 apresentamos 0 mapa de isoteores do Th no embasamento das Bacias de Camamu e Almada usando como dados as medidas das concentrações apresentadas resumidamente na Tabela 6. Este mapa mostra que os teores mais elevados relacionam-se com os granulitos charnockíticos vindo, em seguida, os granulitos metamonzoníticos, o granito de Teolândia, 0 granodiorito de Moenda e os sienitos. Provavelmente, minerais acessórios como monazita e zircão, presentes nessas rochas metamórficas de alto grau, sejam os responsáveis por esses altos teores de tório.

\section{Razões U/Th, U/K e Th/K}

Na Tabela 6 apresentamos as faixas de variação das razões $\mathrm{U} / \mathrm{Th}, \mathrm{U} / \mathrm{K}$ e $\mathrm{Th} / \mathrm{K}$ e 0 valor médio dessas razões nas principais unidades litológicas do embasamento adjacente às bacias de Camamu e Almada. Nos cálculos acima, desconsideráramos os teores dos elementos abaixo de seus respectivos limites de 

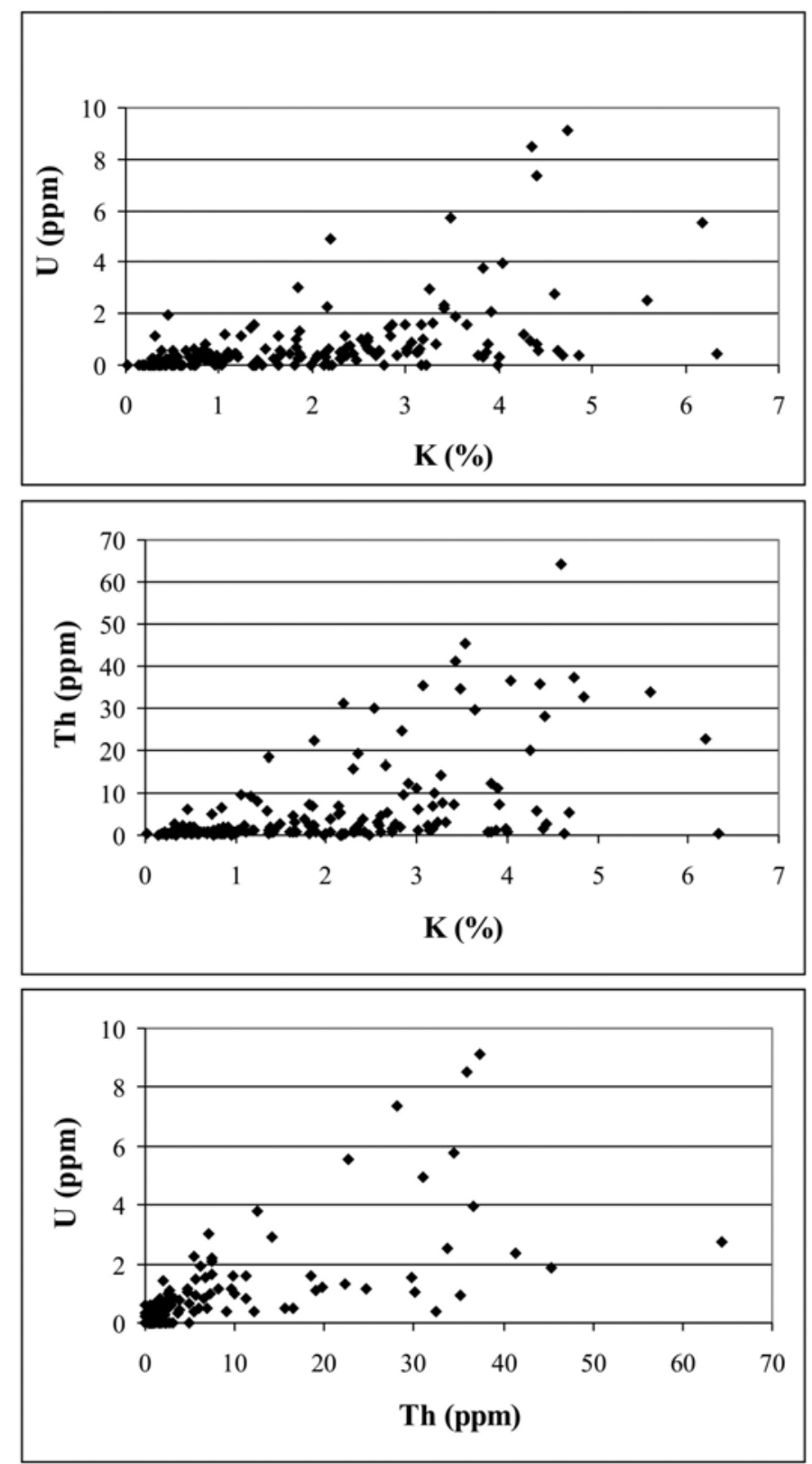

Figura 9 - Correlações entre os teores de U e K, Th e K, e U e Th nas amostras de rocha do embasamento adjacente às bacias de Camamu e Almada.

detecção o que atingiu principalmente amostras dos granulitos metatonalíticos, metamonzoníticos e básicos, principalmente desta última litologia.

Para a razão U/Th, observa-se que os granulitos metatonalíticos, metamonzoníticos, os granulitos básicos e os sienitos formam um grupo onde os valores médios ficam em torno de 0,3, mas os limites máximos são maiores nos duas primeiras litolo- gias e menores nas duas últimas; 0 granulito básico tem o menor limite superior e uma média de 0,4, superior às outras três. Já os charnockitos, granitos de Teolândia e granodioritos de Moenda constituem um outro grupo com médias de 0,09, 0,08 e 0,04, respectivamente, que são cerca de vinte vezes menores que a do grupo anterior e com limites máximos também menores. Estas são as litologias com os maiores teores de $\mathrm{K}$, U e Th e os resul- 

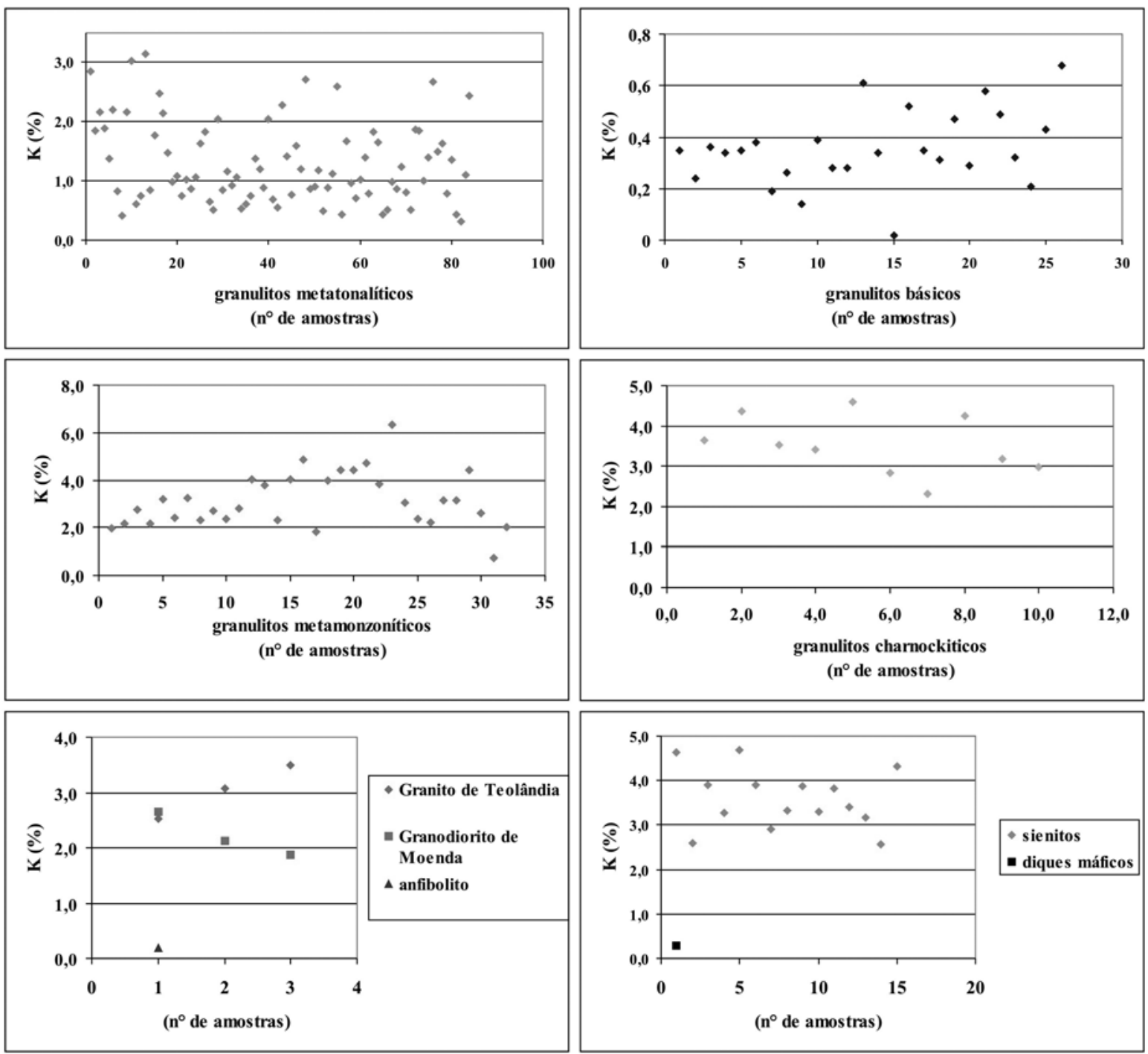

Figura 10 - Dispersão dos teores de K nas principais litologias do embasamento adjacente às bacias de Camamu e Almada.

tados acima indicam que, proporcionalmente, elas concentram mais tório do que urânio.

Na razão U/K, as médias para todas as litologias variam relativamente pouco dentro do erro experimental, de $0,31 \times 10^{-4}$ a $0,78 \times 10^{-4}$, indicando que, ainda que nessas litologias os teores de K e U variem bastante (Tab. 5), a razão entre esses elementos mantém-se praticamente constante.

A razão Th/K cresce com o crescimento do teor de $\mathrm{K}$ nas litologias, como se observa na Tab. 6. Para os granulitos básicos, com teor médio de $\mathrm{K}$ de $0,39 \%$, a razão Th/K média é 1,82. Para os metatonalitos, onde este teor médio é 1,33\%, esta razão cresce para 1,94. Nos charnockitos, granitos de Teolândia, granodioritos de Moenda e sienitos os teores médios de K são 3,46\%, 3,03\%,
2,21 e 3,27\%, respectivamente e as correspondentes razões $\mathrm{Th} / \mathrm{K}$ são $7,86 \times 10^{-4}, 11,1 \times 10^{-4}, 4,85 \times 10^{-4}$ e $6,81 \times 10^{-4}$; apenas os metamonzonitos têm um teor médio alto de $\mathrm{K}(3,29 \%)$ e um valor relativamente baixo da razão Th/K $\left(2,13 \times 10^{-4}\right)$ próximo do valor para os metatonalitos.

\section{Densidade}

As densidades foram determinadas em todas as 205 amostras coletadas e utilizadas no cálculo de suas taxas volumétricas de produção de calor radiogênico. A dispersão das densidades pelas litologias é mostrada na Figura 16 e os valores médios por litologia são apresentados na Tabela 6 com o intervalo de um desvio 


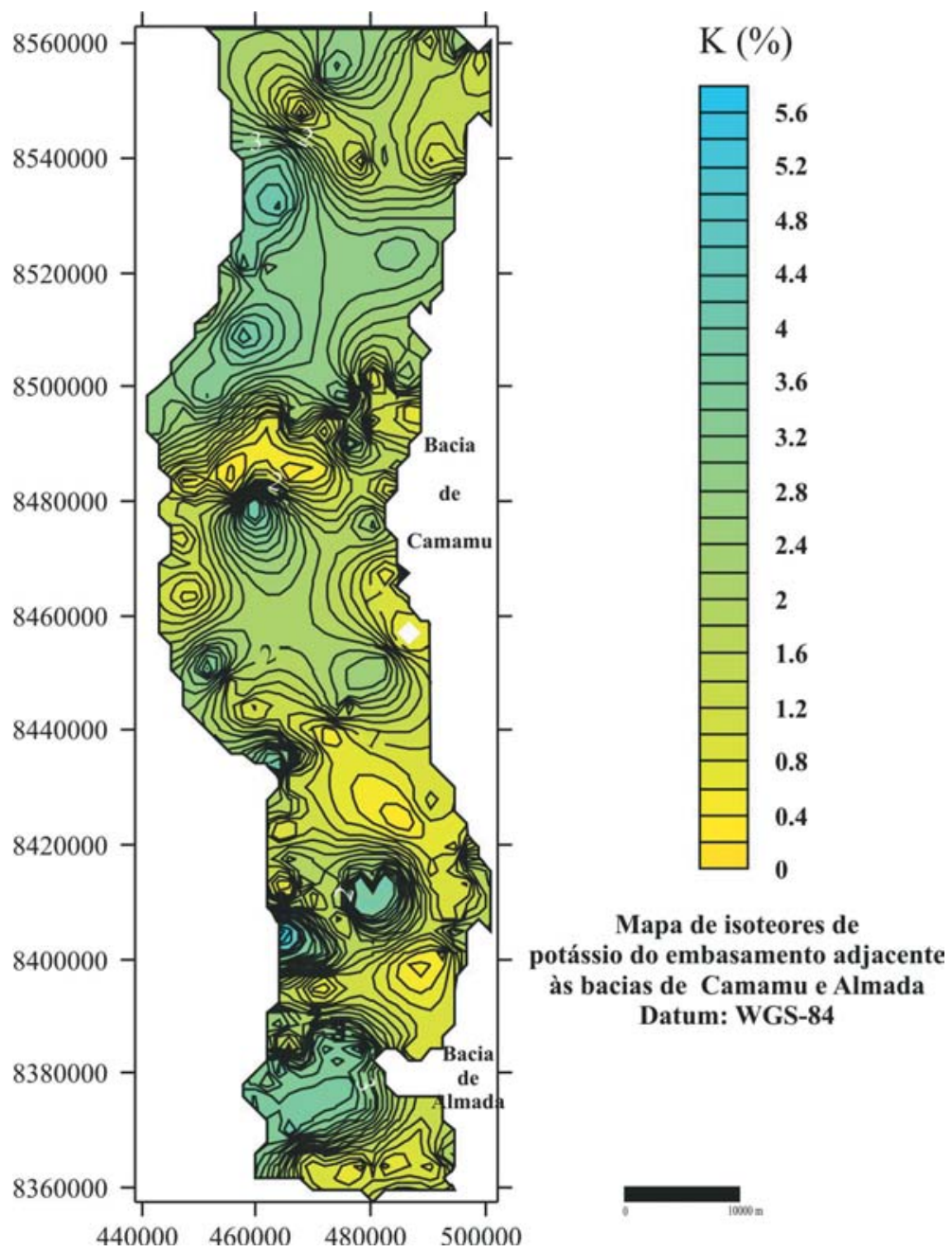

Figura 11 - Mapa dos isoteores de K no embasamento adjacente às bacias de Camamu e Almada.

Tabela 6 - Faixa de variação das razões $U / T h, U / K, T h / K$, e valores médios dessas razões nas principais unidades litológicas estudadas.

\begin{tabular}{|l|c|c|c|c|}
\hline \multirow{2}{*}{ Unidade litológica } & \multirow{2}{*}{$N^{0}$ de amostras } & \multicolumn{3}{|c|}{ Variação da razão - valor médio } \\
\cline { 3 - 5 } & & $\mathrm{U} / \mathrm{Th}$ & $(\mathrm{U} / \mathrm{K}) \times 10^{-4}$ & $(\mathrm{Th} / \mathrm{K}) \times 10^{-4}$ \\
\hline Metatonalito & 94 & $(0,04$ a 1,28$)-0,30$ & $(0,06$ a 3,47$)-0,44$ & $(0,13$ a 14,0$)-1,94$ \\
\hline Granulito básico & 32 & $(0,25$ a 0,63$)-0,41$ & $(0,19$ a 1,14$)-0,63$ & $(0,65$ a 3,89 $)-1,82$ \\
\hline Metamonzonito & 29 & $(0,01$ a 1,48$)-0,34$ & $(0,07$ a 1,92$)-0,39$ & $(0,08$ a 13,5) $-2,13$ \\
\hline Charnockito & 12 & $(0,04$ a 0,24$)-0,09$ & $(0,10$ a 1,95$)-0,59$ & $(0,62$ a 14,0) - 7,86 \\
\hline Granito de Teolândia & 3 & $(0,03$ a 0,17$)-0,08$ & $(0,30$ a 1,64$)-0,78$ & $(9,90$ a 11,9$)-11,1$ \\
\hline Granodiorito de Moenda & 3 & $(0,03$ a 0,06$)-0,04$ & $(0,06$ a 0,70$)-0,44$ & $(2,27$ a 11,9$)-4,85$ \\
\hline Sienito & 16 & $(0,03$ a 1,00$)-0,27$ & $(0,08$ a 1,09$)-0,47$ & $(0,12$ a 4,34$)-6,81$ \\
\hline
\end{tabular}



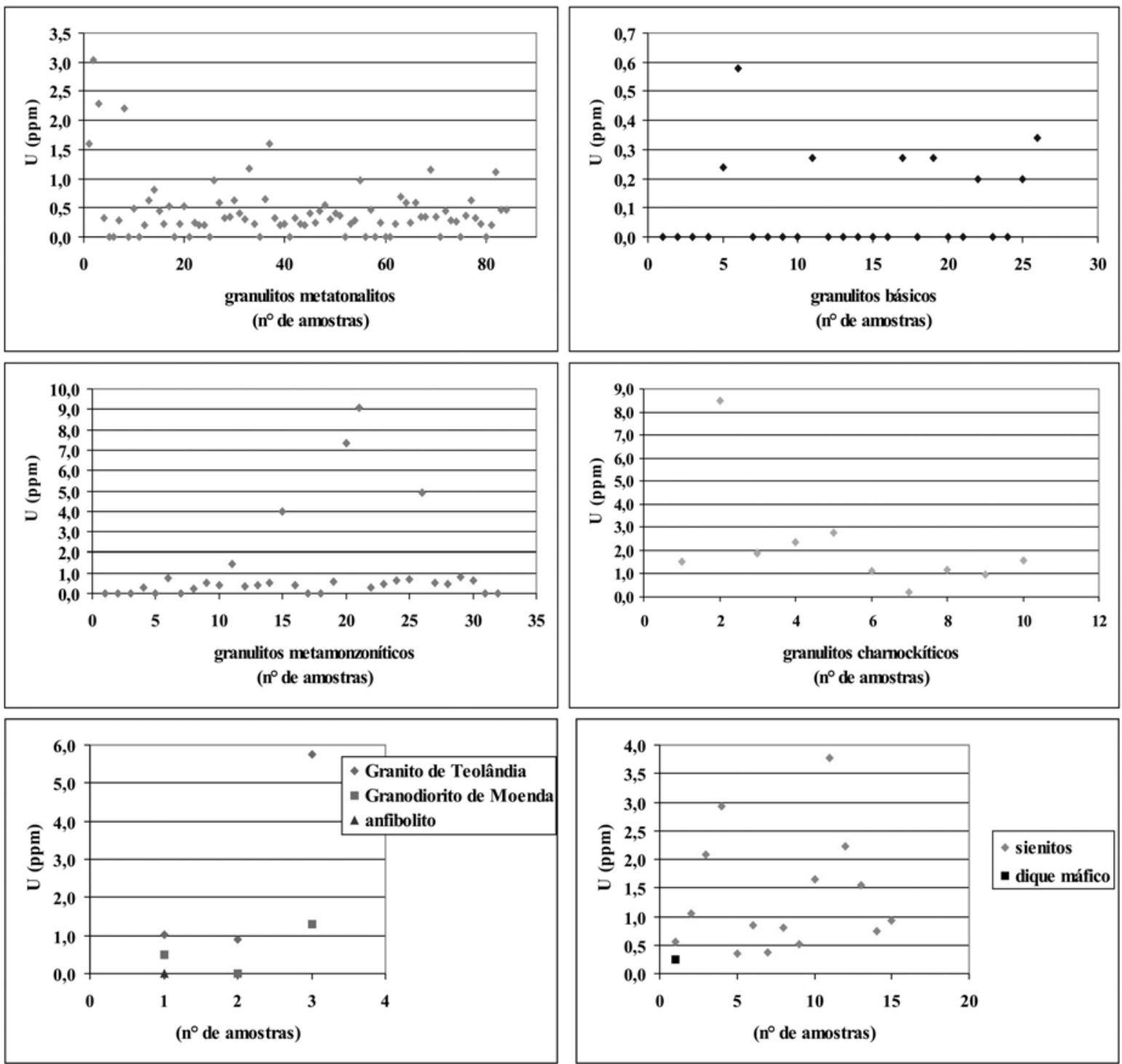

Figura 12 - Dispersão dos teores de U nas principais litologias do embasamento adjacente às bacias de Camamu e Almada.

padrão. Vê-se que as densidades são menores para os granitos e granodioritos, em torno de $2,72 \mathrm{~kg} \mathrm{~m}^{-3}$, e maiores para os granulitos básicos $\left(2,98 \mathrm{~kg} \mathrm{~m}^{-3}\right)$ e para os diques máficos $\left(3,1 \mathrm{~kg} \mathrm{~m}^{-3}\right)$

\section{Taxa de produção do calor radiogênico}

As taxas volumétricas de produção de calor radiogênico obtidas para as principais unidades litológicas do embasamento estudados foram calculadas usando a Equação 6 e os teores e densidades de cada amostra. Na Figura 17 apresentamos os gráficos de dispersão das taxas de produção volumétrica de calor das principais litologias estudadas e na Tabela 6 seus valores médios apre- sentados com o intervalo de um desvio padrão. Vê-se, nesses dados, que as maiores taxas médias de produção de calor são observadas nos granulitos charnockíticos com $3,1 \pm 1,5 \mu \mathrm{W} \mathrm{m}^{-3}$, nos granitos de Teolândia com 3, $27 \pm 0,84 \mu \mathrm{W} \mathrm{m}^{-3}$, nos granodioritos de Moenda com 1, 40 $\pm 0,67 \mu \mathrm{W} \mathrm{m}^{-3}$ e nos sienitos com 1, 20 $\pm 0,51 \mu \mathrm{W}$ m-3.

Os granulitos metamonzoníticos e metatonalíticos mostram taxas intermediárias de produção de calor radiogênico. Os granulitos metamonzoníticos constituem dois grupos, um com taxa média de $0,71 \pm 0,57 \mu \mathrm{W} \mathrm{m}^{-3}$ (90\% das amostras) e outras três amostras com taxa média de 4, $61 \pm 0,83 \mu \mathrm{W} \mathrm{m}{ }^{-3}$. Estes valores altos devem-se aos altos teores de $\mathrm{K}$, $\mathrm{U}$ e Th nes- 


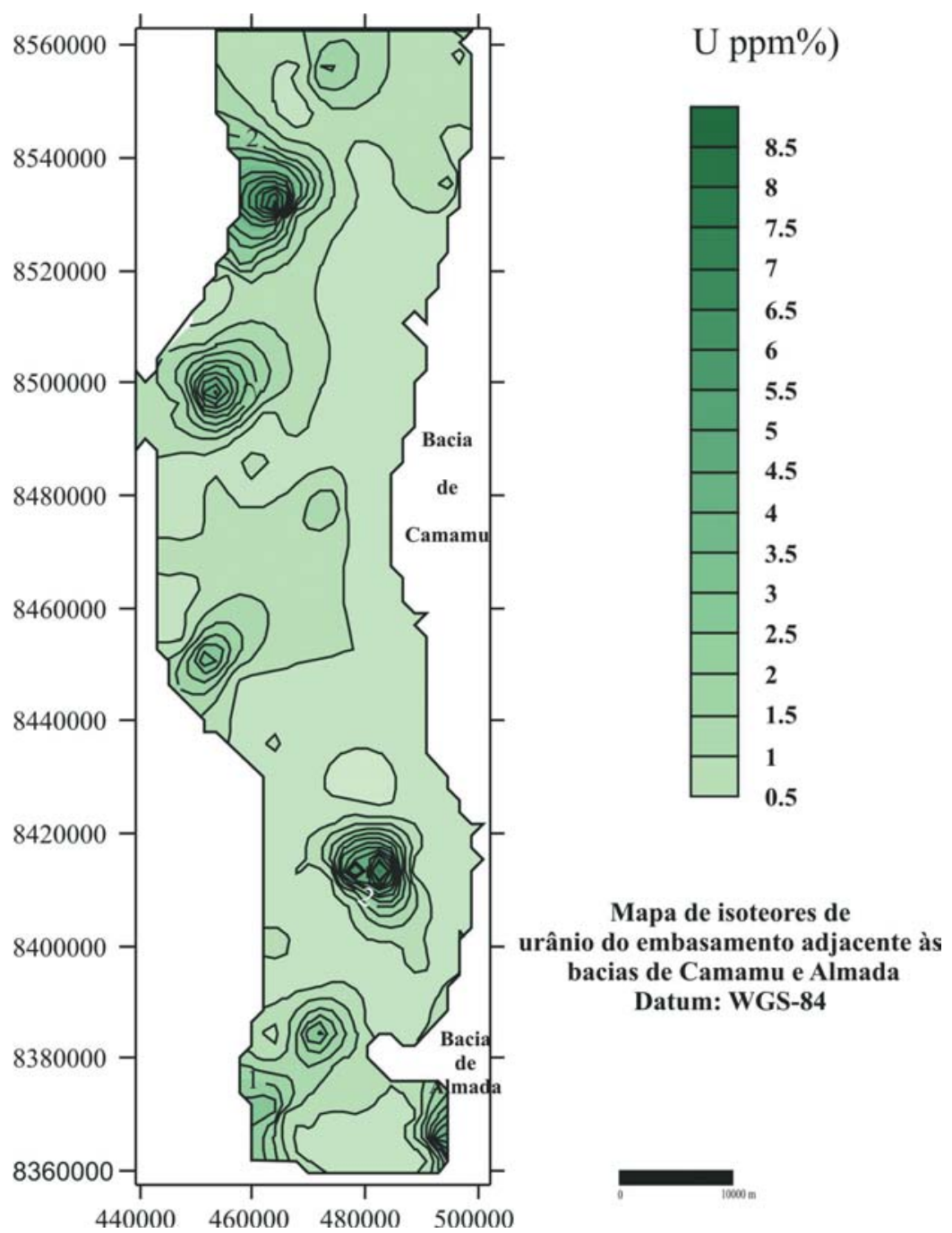

Figura 13 - Mapa dos isoteores de U no embasamento adjacente às bacias de Camamu e Almada.

sas rochas 0 que pode ser atribuído a diferenças nas mineralogias das unidades litológicas avaliadas. Os granulitos metatonalíticos apresentam taxa média de $0,40 \pm 0,30 \mu \mathrm{W} \mathrm{m}^{-3}$, ou de $0,38 \pm 0,27 \mu \mathrm{W} \mathrm{m}^{-3}$ se se considera apenas as taxas menores que $1 \mu \mathrm{W} \mathrm{m}^{-3}$ (97\% das amostras). Os granulitos básicos apresentam as menores taxas de produção de calor com média de $0,120 \pm 0,073 \mu \mathrm{W} \mathrm{m}^{-3}$.

Os granulitos metatonalíticos, os granulitos metamonzoníticos e os sienitos, nesta ordem, são as litologias com presenças mais significativas nas bordas das bacias de Camamu e Almada, sugerindo serem elas as principais litologias responsáveis pela produção de calor radiogênico no embasamento subposto a essas bacias.

Os granulitos metatonalíticos representam a litologia com maior presença no embasamento das bordas das bacias, correndo próximo à borda oeste das duas bacias. Já os granulitos metamonzoníticos correm próximo à borda oeste da bacia de Camamu, tendo aí uma presença destacada, e ocorre numa pequena área do extremo sul da bacia de Almada. Os sienitos ocorrem numa área extensa próxima à borda oeste da bacia de Almada.

Os granulitos básicos provavelmente contribuem muito pouco para o calor produzido no embasamento estudado; eles têm área de ocorrência restrita e apresentam taxas baixas de produção de calor, quando comparadas com as das outras litologias presentes na área.

Mostramos na Figura 17 o mapa de isovalores das taxas de produção de calor radiogênico do embasamento das bacias de Camamu e Almada. 

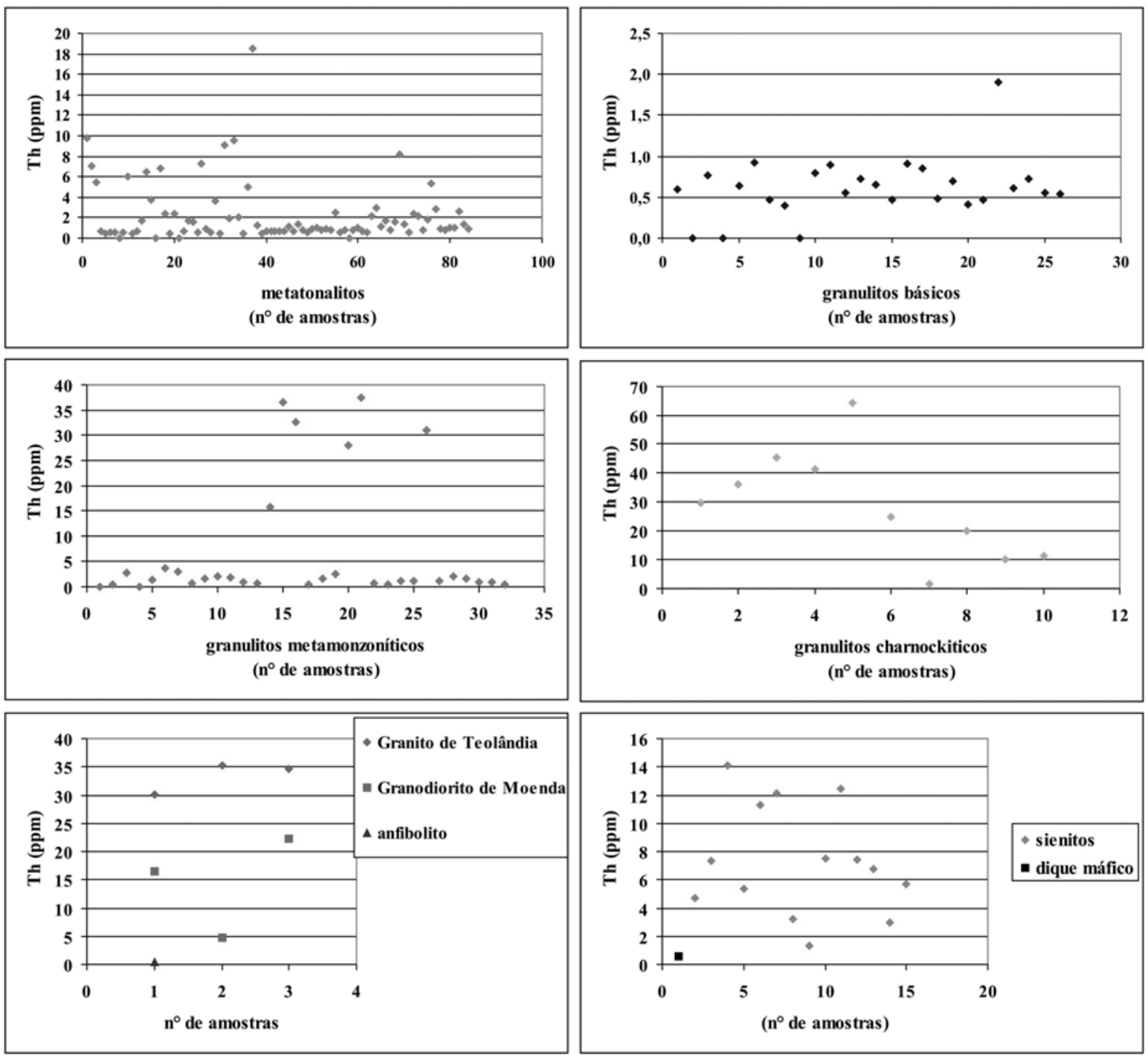

Figura 14 - Dispersão dos teores de Th nas principais litologias do embasamento adjacente às bacias de Camamu e Almada.

\section{CONCLUSÕES}

Com os resultados obtidos neste trabalho podemos concluir que 0 embasamento cristalino adjacente às bacias de Camamu e Almada é predominantemente representado por rochas arqueanas paleoproterozoicas da facies granulito, como os granulitos metatonalíticos, metamonzoníticos shoshoníticos e charnockitos; rochas arqueanas paleoproterozoicas da facies anfibolito, caracterizadas por metagranitos, metagranodioritos e níveis anfibolíticos, e por rochas ígneas neoproterozoicas não metamorfizadas representadas pelos sienitos e diques máficos.

Sob os sedimentos recentes da bacia de Camamu ocorrem, possivelmente, rochas de composição metatonalítica e metamon- zoníticas interdigitadas, já que estas rochas, ocorrendo em maior área na borda da bacia predominam, também, em sua base. É provável, portanto, que a produção do calor radiogênico do embasamento da bacia de Camamu seja devida, principalmente, aos granulitos metatonalíticos e aos granulitos metamonzoníticos.

Já no embasamento da bacia de Almada, a produção do caIor radiogênico de seu embasamento dever-se-á, principalmente, aos granulitos metatonalíticos, aos sienitos neoproterozóicos e aos granulitos metamonzoníticos, que são, nesta ordem, as litologias com maior presença observada ao longo da borda desta bacia.

Os granulitos charnockíticos, o granito de Teolândia, o granodiorito de Moenda e, numa certa medida, os sienitos neoprote- 


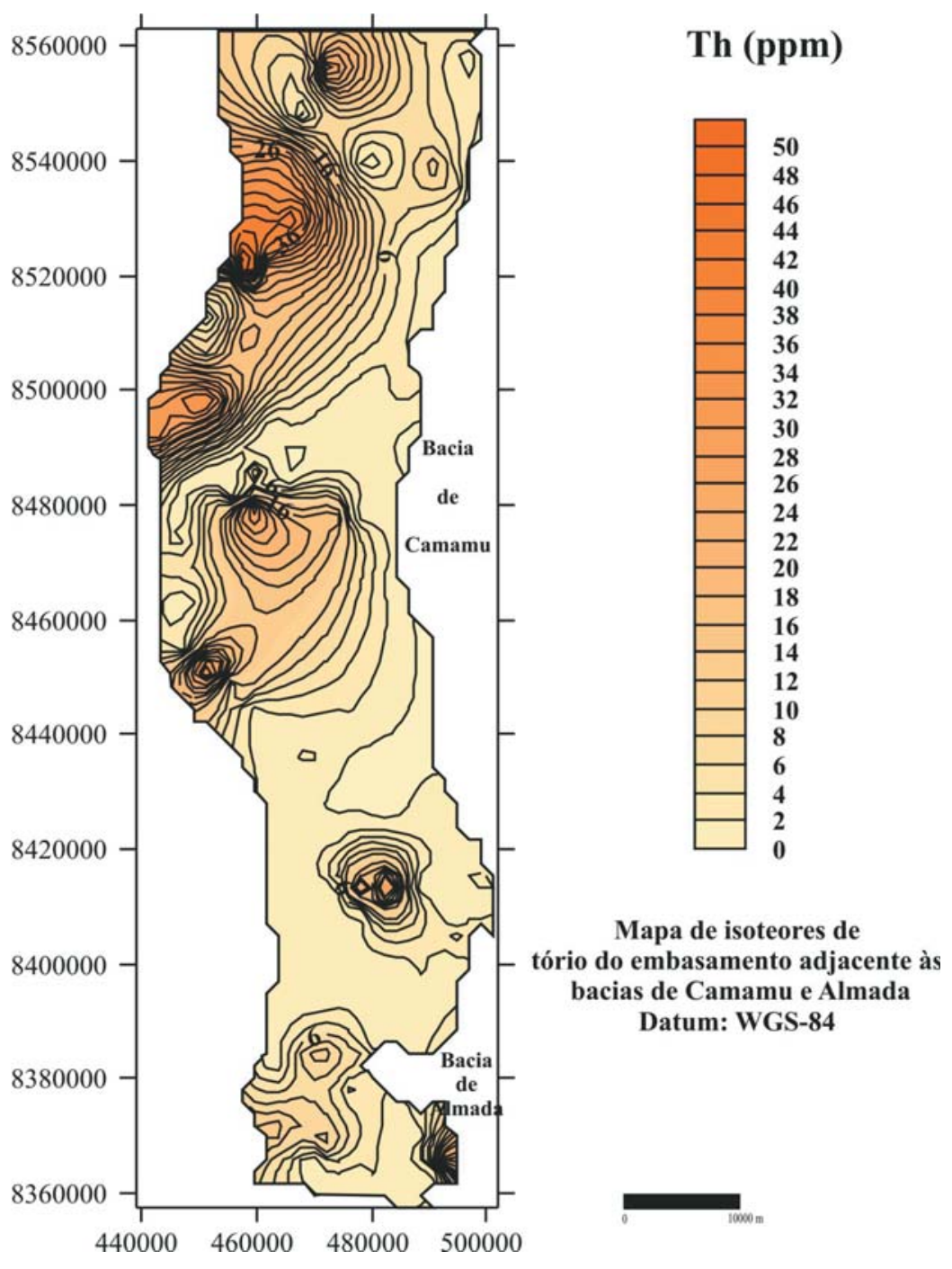

Figura 15 - Mapa dos isoteores de Th no embasamento adjacente às bacias de Camamu e Almada.

rozóicos são as unidades litológicas que apresentam as maiores taxas de produção de calor. Contudo, eles pouco devem contribuir para a produção de calor sob as bacias porque suas abrangências, em termo de área, são bem menores que as das outras litologias.

Para as três litologias predominantes, os valores médios das taxas de produção do calor radiogênico são de $0,41 \pm$ $0,30 \mu \mathrm{W} \mathrm{m}^{-3}$ para os granulitos metatonalíticos, de $0,71 \pm$ $0,57 \mu \mathrm{W} \mathrm{m}^{-3}$ para os granulitos metamonzoníticos e de $1,20 \pm$ $0,51 \mu \mathrm{W} \mathrm{m}^{-3}$ para os sienitos. Como o embasamento cristalino das bacias de Camamu e Almada é constituído, em sua maioria, por rochas arqueanas e paleoproterozóicas da facies granulito, possivelmente, a taxa de produção de calor radiogênico não sofrerá variação apreciável com a profundidade, já que este tipo de ambiente metamórfico caracteriza a base da crosta continental.

\section{AGRADECIMENTOS}

Este trabalho foi custeado pelo projeto GEOTERM (convênios FINEP 011740, PETROBRAS 011772) e desenvolvido com a infraestrutura de apoio do CPGG-UFBa. Os autores agradecem à FINEP, PETROBRAS, CPGG e ANP PRH-8, esta pela bolsa concedida à autora Najara Sapucaia durante a execução deste trabalho.

\section{REFERÊNCIAS}

ADAMS JAS \& GASPARINI P. 1970. Gamma-Ray Spectrometry of Rocks. Methods in Geochemistry and Geophysics Series. Elsevier Publishing Company.

ALMEIDA FFM de. 1977. 0 cráton do São Francisco. Rev. Bras. Geoc., 7(4): 349-364. 

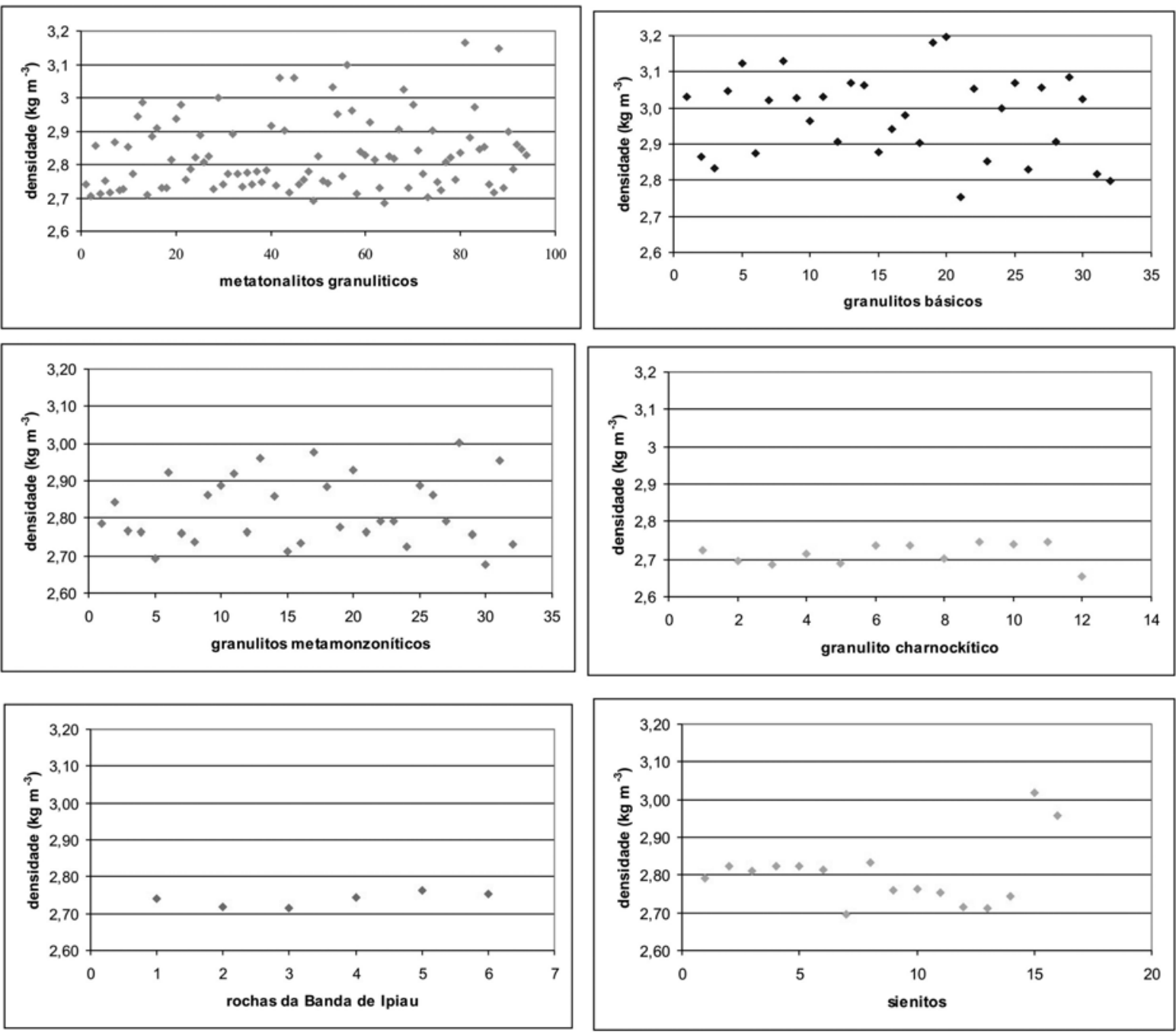

Figura 16 - Dispersão dos valores da densidade das principais unidades litológicas do embasamento adjacente às bacias de Camamu e Almada.

ALVES JÚNIOR PB. 2004. Determinação de perfis de taxa de produção de calor radiogênico em poços da Bacia do Recôncavo. Trabalho de Graduação, Universidade Federal da Bahia.

ARCANJO JBA, BARBOSA JSF \& OLIVEIRA JE. 1992. Caracterização petrográfica e metamórfica dos granulitos do arqueano/proterozóico inferior da região de Itabuna - Brasil. Rev. Bras. Geoc., 22(1): 47-55.

ARCANJO JBA, OLIVEIRA JE, GOMES RAAD, MENESES NRF, TEIXEIRA LR, SOUZA JD, PADILHA AV, DELGADO IM, SANTOS RA, MELO RC \& FERNANDES PCA. 1997. Programa de levantamentos geológicos básicos do Brasil, Itabuna, Folha SD-24-Y-B-VI, vol. 1, 276 pp., CPRM, Brasília.

BARBOSA JSF. 1986. Constitution lithologique et metamorphique de la region granulitique du sud de Bahia, Bresil. Tese de doutorado, Université Paris VI. França.
BARBOSA JSF. 1989. Química mineral utilizada na identificação da facies metamórficas da região granulítica do sul da Bahia, Brasil. Rev. Bras. Geoc., 19(3): 350-366.

BARBOSA JSF \& FONTEILLES M. 1991. Síntese sobre o metamorfismo da Região Granulítica do sul da Bahia. Rev. Bras. Geoc., 21(4): 328-341. BARBOSA JSF \& SABATÉ P. 2002. Geological features and the paleoproterozoic collision of four archean crustal segments of the São Francisco Craton, Bahia, Brazil: a synthesis, Acad. Bras. Cienc., 74(2): 343-359.

BARBOSA JSF \& SABATÉ P. 2003. Colagem paleoproterozoica de placas arqueanas do Cráton do São Francisco na Bahia. Rev. Bras. Geoc., 33(1): 7-14.

BARBOSA JSF, SILVA FCA, IYER SS \& SAPUCAIA NS. 1998. Petrological and geoquimical characteristics of the granulitic terrain of Brejões, Bahia, Brazil. International Geosciences Journal, Brasil, 1(3/4): 343-356. 

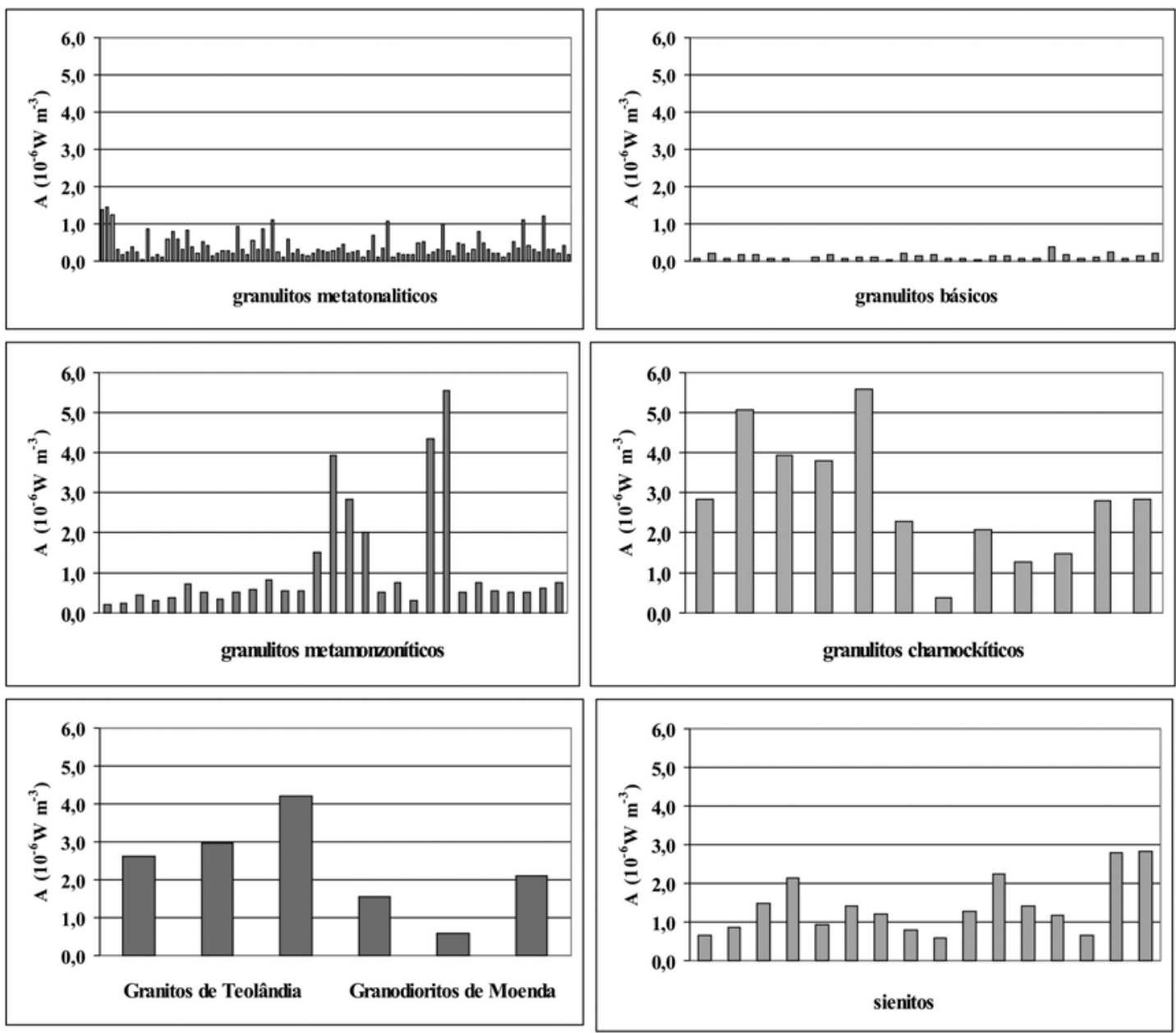

Figura 17 - Dispersão de taxa de produção volumétrica de calor nas principais unidades litológicas do embasamento adjacente às bacias de Camamu e Almada.

BARBOSA JSF, GOMES LCC, MARINHO MM \& SILVA FCA. 2003. Geologia do segmento sul do Orógeno Itabuna-Salvador-Curaçá. Rev. Bras. Geoc. 33(suplemento): 33-48.

BARBOSA JSF, MARTIN H \& PEUCAT J. 2004. Paleoproterozoic domeforming structures related to granulites - facies metamorphism, Jequie Block, Bahia, Brazil. Petrogenetic Approaches, Precambrian Research, 135: 105-131.

CORDANI UG. 1973. Evolução geológica da faixa costeira do Brasil entre Salvador e Vitória. Tese de livre docência, USP.

COSTA LAM \& MASCARENHAS JF. 1982. The high-grade metamorphic terrains in the interval Mutuípe - Jequié. archean and lower proterozoic of east - central Bahia, In: International Symposium on Archean and Early Proterozoic Geologic Evolution Metalogenesis, 1: 19-37.

CURRIE LA. 1968. Limits for qualitative detection and quantitative determination. Application to radiochemistry. Analytical Chemistry, 40(3): 586-593.
FORNARI A \& BARBOSA JSF. 1992. A suíte enderbítica-charnockítica da região de Mutuípe - Ba, Em Simp. Reg. Geol. Bahia - Sergipe, 1: 87-91.

GONÇALVES FTT, BEDREGAL RP, COUTINHO LFC \& MELLO MR. 2000. Petroleum system of the Camamu-Almada basin: a quantitative modeling approach. In: Petroleum systems of South Atlantic margins. The American Association of Petroleum Geologists, 73: 257-271.

HASAN M, BÓDIZS D \& CZIFRUS SZ. 2002. A simplified technique to determine the self-absorption correction for sediments samples. Applied Radiation and Isotopes, 57: 915-918.

KETCHAM RA. 1996. An improved method for determination of heat production with gamma-ray scintillation spectrometry. Chem. Geol., 130: 175-194.

LA ROCHE H, LETERRIER J, GRAND-CLAUDE P \& MARCHAL MA. 1980. Classification of volcanic and plutonic rocks using R1-R2 diagram majorelements analysis its relationships with current nomenclature. Chemical Geology, 29: 183-210. 

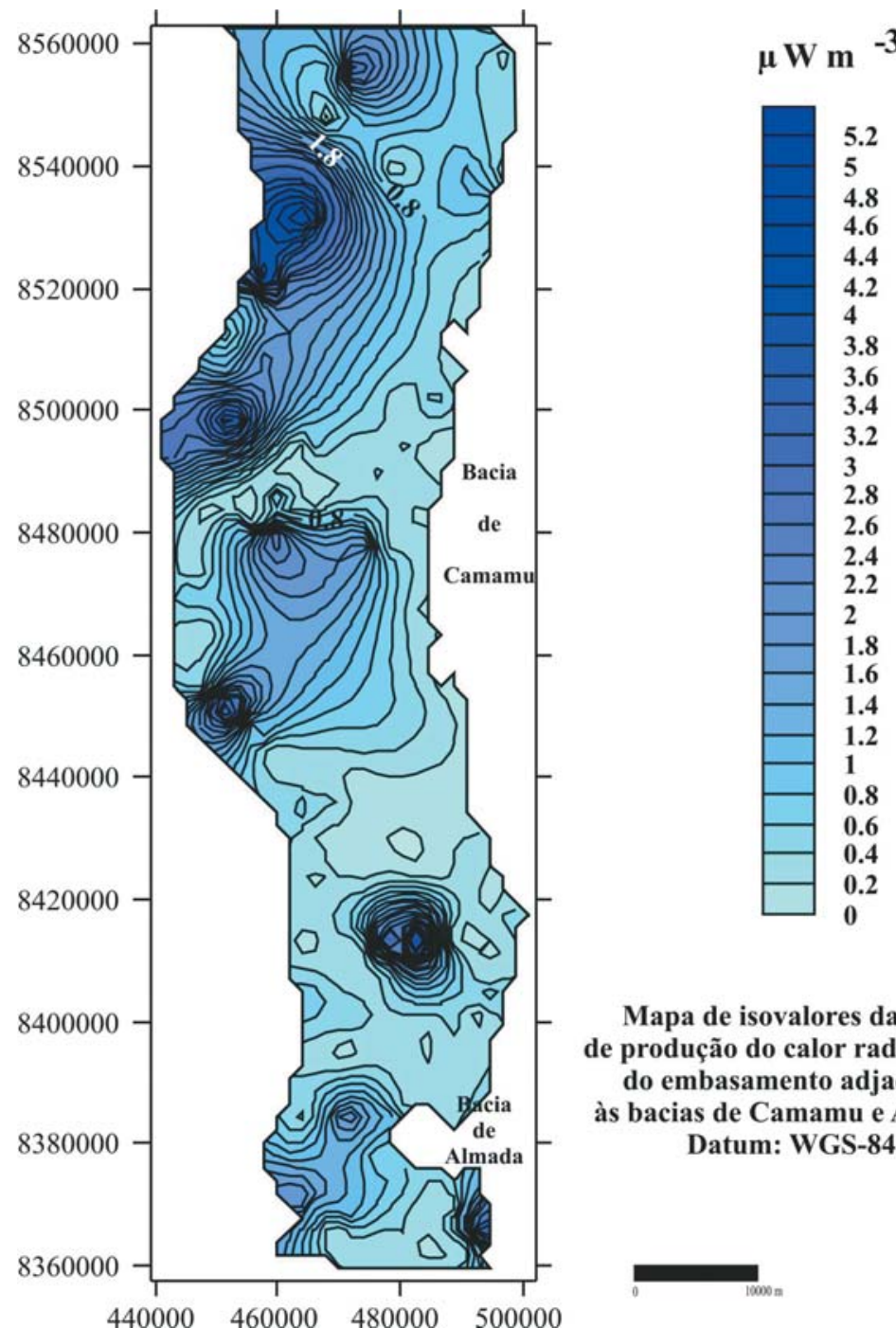

Mapa de isovalores da taxa de produção do calor radiogênico

do embasamento adjacente às bacias de Camamu e Almada Datum: WGS-84

Figura 18 - Mapa de isovalores da taxa de produção volumétrica de calor do embasamento adjacente às bacias de Camamu e Almada.

LE MAITRE RW. 1989. A classification of igneous rocks and glossary of terms, Blackwell, Oxford.

MIRANDA LLF, SOARES JV, CRUZ MJM \& MORAES AMV. 1985. Projeto Ubaira - Santa Inês, SME/CBPM. Relatório final 1.

O'CONNOR JT. 1965. A classification for quartz-rich igneous rocks based on feldspar ratios. U. S. Geol. Surv. Prof. Pap., 525/B: 79-84.

PEDREIRA AJ, ARAÚJO AAF, SILVA BCE, PEDROSA CJ, ARCANJO JBA, OLIVEIRA JE, GUIMARÃES JT, BRANCO PM, AZEVEDO RR, SOUZA SL, NEVES JP, MASCARENHAS JF \& BLADE LV. 1975. Projeto Bahia II, Relatório Final-CPRM.

RYBACH L. 1988. Amount and significance of radioactivity at sources in sediments, Ed. Technip.

SAPUCAIA NS. 2004. Diferenciação litológica, teores de potássio, urânio e tório e taxa de produção do calor radiogênico do embasamento cristalino das bacias de Camamu e Almada. Dissertação de Mestrado em Geofísica, UFBA, 72 pp.

SIGHINOLFI GP \& SAKAI T. 1977. Uranium and thorium in archean granulite facies terrains of Bahia (Brazil). Geochim. J., 11: 33-39.

STREICKEISEN A. 1975. How should charnockitic rocks be named? Geologie des Domaines Cristalines. Liege. Soc. Geol. Belg., Centenaire de la Societe Geologique de Belgique. 


\section{NOTAS SOBRE OS AUTORES}

Najara Santos Sapucaia é mestra em Geofísica, bacharela em Geologia e doutoranda em Geologia pela Universidade Federal da Bahia. Atualmente trabalha como geóloga-geofísica na firma Petrorecôncavo. É filiada à SBGf.

Roberto Max de Argollo é doutor em Ciências, área Geofísica, pela Universidade Federal da Bahia, mestre em Oceanografia pela Universidade de Rhode Island, Estados Unidos, e bacharel em Física pela então Universidade do Brasil. É professor titular do Instituto de Física e pesquisador do Centro de Pesquisa em Geofísica e Geologia, ambos da UFBa. Coordenou o projeto Geoterm (2002-2005) financiado pela Finep em parceria com a Petrobras para estudos geotérmicos em bacias sedimentares. Suas áreas de interesse são fluxo térmico, calor radiogênico e cronologia de sedimentos usando chumbo-210 e césio-137. É filiado à SBPC, SBGf e SBF.

Johildo Salomão Figueirêdo Barbosa é doutor em Geologia pela Universidade Pierre et Marie Curie, tem pós-doutorado nas Universidades francesas de Rennes e Clermont-Ferrand e é mestre e bacharel em Geologia pela Universidade Federal da Bahia. É professor titular do Instituto de Geociências e pesquisador do Centro de Pesquisa em Geofísica e Geologia, ambos da UFBa e pesquisador 1C do CNPq. É coordenador nacional do acordo CAPES/COFECUB, Brasil-França, projetos 158/94 e 381/02, ambos sobre geologia isotópica e geocronologia do embasamento do Cráton do São Francisco na Bahia. Suas áreas de interesse são petrologia e geologia regional. É filiado à SBG. 